\title{
Recycling of Nuclear Spent Fuel with AIROX Processing
}

\author{
Contributing Authors \\ DOE: \\ D. Majumdar \\ EG\&G Idaho: \\ S. N. Jahshan \\ C. M. Allison \\ P. Kuan \\ WINCO: \\ T. R. Thomas
}

Editor

D. Majumdar

Published December 1992

Prepared for the

U.S. Department of Energy DOE Idaho Fleld Office 


\section{DISCLAIMER}

Portions of this document may be illegible electronic image products. Images are produced from the best available original document. 


\section{ABSTRACT}

This report examines the concept of recycling light water reactor (LWR) fuel through use of a dry-processing technique known as the AIROX (Atomics International Reduction 0xidation) process. In this concept, the volatiles and the cladding from spent LWR fuel are separated from the fuel by the AIROX process. The fuel is then reenriched and made into new fuel pins with new cladding. The feasibility of the concept is studied from a technical and high level waste minimization perspective. 



\section{EXECUTIVE SUMMARY}

This report examines the concept of recycling light water reactor (LWR) fuel through use of a dry-processing technique known as the AIROX (Atomics International Reduction 0xidation) process. In this concept, the volatiles and the cladding from spent LWR fuel are separated from the fuel by the AIROX process. The fuel is then reenriched and made into new fuel pins with new cladding. The feasibility of the concept is studied from a technical and high level waste minimization perspective. Following are highlights of the study.

1. Reconstituting and recycling spent fuel via the AIROX process is considered technically feasible based on prior development work done by Atomics International.

2. Neutronics studies of AIROX-processed fuel show that reactivity reduction due to the presence of fission products is small and the recycled fuel can be profitably used in LWRs.

- Reactivity coefficient comparisons between a virgin and recycled core indicate that existing reactivity control mechanisms will suffice.

- The calculated moderator temperature coefficients remain within acceptable design limits.

3. Licensing of AIROX recycled fuel for commercial power plant use should not present an insurmountable difficulty. The characteristics of the recycled fuel can be expected to be similar to those of high-burnup fuels. This study indicates that:

- For design basis accident conditions, the results from existing fuel behavior programs, in combination with in-reactor lead rod programs, should be sufficient to qualify AIROX processed fuel.

- For severe accident conditions, analysis beyond that required for 
typical new fuel designs will be needed to ensure that source term margins remain within licensing limits. This is because of the somewhat unique fuel chemistry of the AIROX fuel and its effect on the source term.

4. From a high-level waste management point of view, the AIROX recycling scheme has several benefits:

- It supports better resource utilization and will generate more electricity for the same amount of final spent nuclear fuel.

- It will result in less volume of total high-level waste that must be sent to a repository than the once-through cycle.

- It would reduce U.S. utility needs for rapid expansion of on-site spent fuel storage.

- It may provide more flexibility in the U.S. Department of Energy's monitored retrievable storage and repository programs.

5. Considerable developmental work will be needed before a prototypical AIROX plant could be developed. Notable among these are:

- Conducting tests on spent fuel recycled and irradiated to a high burnup in a power reactor.

- Developing a remote mixing and sampling technique for spent-fuel and virgin feedstock powder.

- Designing and testing an integrated off-gas clean-up system.

- Designing suitable robotic systems for service in highly radioactive and dusty environments.

- Development of a non-destructive fuel assay instrument that will satisfy safeguards requirements. 
6. An aggressive AIROX fuel recycling program could reduce the total U.S. high level waste by about 30\% (for the new-reactor-order case) even when Greater Than Class C (GTCC) waste generated by the AIROX process is included

- The waste generated per metric ton of initial heavy metal. (MTIHM) of spent fuel would be 0.29 MT of cladding and hardware and 0.1 MT of semi-volatiles as GTCC waste, in the form of ingots and glass wastes, respectively.

- If the separated cladding and hardware can be further recycled in a nuclear facility or the repository, the total high level waste that must be sent to a repository will be reduced by more than half.

- Partitioning of ${ }^{129} \mathrm{I}$ and some burning of ${ }^{99} \mathrm{Tc}$ in the recycled fuel could provide about $50 \%$ reduction in the calculated population dose from a geologic repository, if all spent fuel were recycled.

7. The heat load from AIROX fuel would be similar to high-burnup fuel; consequently, AIROX-reprocessed fuel would be hotter than normal oncethrough spent fuel. The AIROX process produces fewer, but hotter, spent fuel assemblies. This must be factored into the repository design.

8. The AIROX process has not been tested beyond the laboratory scale. In addition, effective technologies must be developed to assist utilities in the inspection and quality assurance programs for utilization of the recycled fuel. 


\section{ACKNOWLEDGMENTS}

The editor expresses his sincere thanks to Mr. Larry Leach, who inspired and strongly supported AIROX work at the INEL when he was at the Idaho Field office. Thanks are also due to Mr. Herbert Feinroth, who has foreseen the importance of the AIROX process for the nuclear power industry and who has been a constant source of encouragement for work in this area. William Owca has helped tremendously in improving the document by his constructive criticism and suggestions on the first draft. His help is gratefully acknowledged. Nadine Wade is thanked for her work in putting this document together in a timely fashion. 


\section{CONTENTS}

ABSTRACT

i i i

SUMMARY . . . . . . . . . . . . . . . . . . . . . . v

ACKNOWLEDGMENTS . . . . . . . . . . . . . . . . . . . . viii

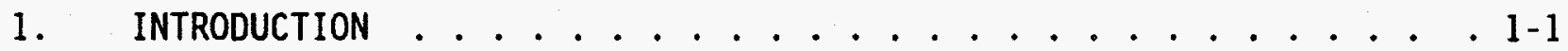

1.1 International Interest in Dry Processing and Recycling of

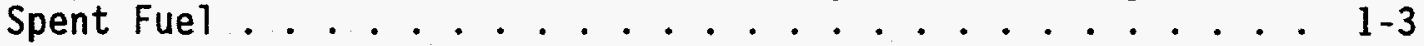

1.2 Safeguards Issues . . . . . . . . . . . . . 1-5

1.3 Report Organization ................. 1-6

1.4 References...................... . . 1-7

2. THE AIROX PROCESS . . . . . . . . . . . . . . . . . 2-1

2.1 Prior AIROX Studies . . . . . . . . . . . . . 2-1

2.2 Chemical Engineering Concepts . . . . . . . . . . . 2-3

2.2.1 AIROX Process Waste Generation Rates . . . . . . 2-5

2.2.2 Prototypical AIROX Facility . . . . . . . . . 2-6

2.3 AIROX Cost Estimates ................. . . 2-10

2.4 AIROX Process Research and Development Needs . . . . . . . 2-13

2.4.1 Receive, Assay, Disassemble Fuel Assemblies . . . . 2-13

2.4.2 Hole Punch Cladding . . . . . . . . . . . . . 2-13

2.4.3 Pulverize/Declad at $400-600^{\circ} \mathrm{C}$ with $\mathrm{O}_{2}$ and $\mathrm{H}_{2}$ Cycles . . 2-13

2.4.4 Ball $\mathrm{Mill}_{\mathrm{UO}}$ to $10 \mu \mathrm{m}$, Blend Spent and Virgin $\mathrm{UO}_{2}$. . 2-14

2.4.5 All Unit Operations............... 2-14

2.4.6 Recover Volatile ${ }^{3} \mathrm{H}, \mathrm{I}, \mathrm{Xe}, \mathrm{Kr}, \mathrm{C} . . .2 . . .2-15$

2.5 References...................... 2-16

3. REACTOR OPERATION AND SAFETY ISSUES . . . . . . . . . . . . . 3-1

3.1 Reactivity Comparisons of Virgin and AIROX Fuel Assemblies . . 3-1

3.2 Power Peaking and Other Reactor Core Issues . . . . . . 3-6

3.3 Fuel Behavior Studies . . . . . . . . . . . . . 3-12

3.3.1 LWR Fuel Behavior Data Base . . . . . . . . . . 3-12

3.3.2 LWR Fuel Behavior Models ............ 3-13 
3.3.3 Ongoing LWR Programs Incorporating Fuel Behavior Studies . . . . . . . . . . . . . . . 3-15

3.3.4 Fuel Behavior Mechanisms Requiring Specific Evaluation for AIROX-Processed Fuel .. . . . . . . . . 3-15

3.3.5 Implications for the Licensing of AIROX Fuel ... . 3-16

3.4 References . . . . . . . . . . . . . . 3-16

4. WASTE MANAGEMENT ASPECTS OF AIROX PROCESSING . . . . . . . . . . 4- 1

4.1 Disposition of Wastes Generated Via the AIROX Process . . . 4-1

4.2 AIROX-Reprocessed Spent Fuel from a Repository Perspective . . 4-4

4.3 Impact of AIROX Reprocessing on U.S. Spent Fuel Waste

Reduction................... . . 4-6

4.3.1 AIROX Recycle Model and Assumptions . . . . . . . . . 4-6

4.3.2 AIROX Recycle Model Predictions............ 4-8

4.4 References . . . . . . . . . . . . . . . . . . 4-13

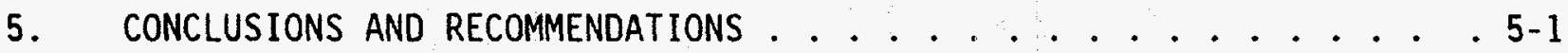

$x$ 


\section{FIGURES}

2-1. Unit operations in the AIROX process ......... 2-4

3-1. Comparison of the infinite multiplication factor, $k-\infty$, for virgin 4.3 wt.\% ${ }^{235} \mathrm{U}$-enriched fuel and AIROX-recycled fuel with $3.3 \mathrm{wt} . \%{ }^{235} \mathrm{U}$ (reprocessed from $3.2 \mathrm{wt} . \%$ virgin fuel with $33 \mathrm{MWd} / \mathrm{kg}$ burnup). ................ 3-. . . 3

3-2. Comparison of the infinite multiplication factor, $k-\infty$, for virgin $4.3 \mathrm{wt} . \%{ }^{235} \mathrm{U}$-enriched fuel and AIROX-recycled fuel with $4.0 \mathrm{wt} . \%{ }^{239} \mathrm{Pu}$ (reprocessed from $3.2 \mathrm{wt} . \%$ virgin fuel with $33 \mathrm{MWd} / \mathrm{kg}$ burnup). ................ . . . . . . 3

3-3. Comparison of the fissile ${ }^{235} U$ inventory for the virgin fuel and the two reprocessed fuels of Figures 3-1 and 3-2 ..... 3-4

3-4. Comparison of the fissile Pu inventory (total ${ }^{239} \mathrm{Pu}$ and ${ }^{241} \mathrm{Pu}$ ) for the virgin fuel and the two reprocessed fuels of Figures 3-1 and $3-2 \ldots \ldots . \ldots . . \ldots 3-\ldots$

3-5. The infinitely repeated assembly multiplication factor as a function of burnup for the reprocessed fuel and for the virgin fuel at 3.3 and $4.3 \mathrm{wt} . \%$ enrichment ............ 3-5

3-6. Thermal and fast flux densities throughout the fuel life for virgin 3.3 and $4.3 \mathrm{wt} . \%{ }^{235} \mathrm{U}$-enriched fue 1 burned at $600 \mathrm{ppm}$ boron and $36 \mathrm{w} / \mathrm{gu} \ldots \ldots \ldots \ldots . . \ldots \ldots$

3-7. Thermal and fast flux densities throughout the fuel life for AIROX-reprocessed $3.3 \mathrm{wt} . \%{ }^{235} \mathrm{U}$-enriched fuel burned at 0 and $600 \mathrm{ppm}$ boron and $36 \mathrm{~W} / \mathrm{gU}$.

3-8. Thermal and fast flux densities throughout the fuel life for AIROX-reprocessed $4.0 \mathrm{wt} . \%{ }^{239} \mathrm{Pu}$-enriched fuel burned at $600 \mathrm{ppm}$ boron and $36 \mathrm{~W} / \mathrm{gU} \ldots \ldots . . \ldots 3-8$

4-1. Comparison of decay heat levels from AIROX fuel, standard $33 \mathrm{GWd} /$ MTU burnup fuel, and $55 \mathrm{GWd} /$ MTU fuel. . . . . . . . 4-5

4-2. AIROX recycle model ................ 4-7

4-3. DOE projections of spent fuel discharges through 2040 . . . . 4-9

4-4. Wastes from once-through versus AIROX recycle scenarios for the no-new reactor case ............... 4-11

4-5. Wastes from once-through versus AIROX recycle scenarios for the upper-reference reactor case. 


\section{TABLES}

2-1. Amounts of LLW and GTCC wastes and stored fission products generated per MT of spent fuel processed by AIROX . . . . . . 2-7

3-1. Comparison of rod worth [100 (ln $\left.\left.k_{2} / k_{1}\right)\right]$ (B4C rod clusters) in standard Westinghouse $17 \times 17$ pin fuel assemblies at full power with full xenon concentrations at beginning, middle, and end of life. . 3-9

3-2. Comparison of moderator temperature coefficient ( $\mathrm{pcm} / \mathrm{K})$ at zero power, $600 \mathrm{ppm}$ boron, at beginning, middle, and end of $1 \mathrm{ife}$. . 3-9

3-3. Comparison of end-of-reactor-cycle (19 MWd/kgU) reactivity data for the equilibrium cycle loading with $100 \%$ virgin fuel (initial enrichment $4.3 \mathrm{wt} \% 235 \mathrm{U}$ ) to the end-of-reactor-cycle reactivity data of equilibrium cycles loaded with reprocessed fuel in

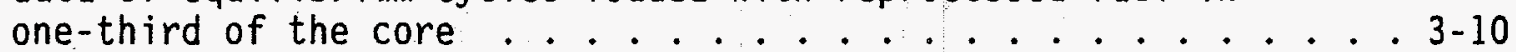




\section{RECYCLING OF NUCLEAR SPENT FUEL WITH AIROX PROCESSING}

\section{INTRODUCTION}

The Idaho National Engineering Laboratory (INEL) undertook an effort in FY 1992 to examine the possibilities for minimizing both low- and high-level waste from commercial nuclear power plants. ${ }^{1-1}$ The ultimate idea is to conceptualize a minimum-waste power reactor.

The first generation of commercial nuclear power systems was designed to optimize safety and power cost, while utilizing technology developed for submarine propulsion. Tremendous progress has been made in the last decade in the areas of commercial nuclear power operation and safety. However, the issue now, and for the future, is pollution prevention and waste minimization. The disposal of radioactive wastes has become the most important factor for nuclear power. The driving concept for our work is that waste must be minimized with improved processes for operation, new technologies, and designs over the entire fuel cycle, from mining to final disposal. This report explores an idea for minimizing high-level waste.

This work examines whether or not high-level waste from commercial power reactors can be reduced by recycling spent fuel via the Atomics International Reduction 0xidation (AIROX) process. ${ }^{1-2}$ The AIROX process is a dry oxidationreduction process for the oxide fuel that uses only gaseous and solid materials. In this process, the cladding, volatile fission products, and other fuel constituents are separated using pyrochemical reactions performed at temperatures of 400 to $600^{\circ} \mathrm{C}$. Oxidation transforms the $\mathrm{VO}_{2}$ ceramic fue 1 pellets into granular $\mathrm{U}_{3} \mathrm{O}_{8}$, which expands the volume of the fuel, rupturing the cladding. The granular oxide fuel then easily separates from the cladding. Volatile fission products $\left(\mathrm{Kr}, \mathrm{Xe}, \mathrm{I}\right.$, and $\left.{ }^{3} \mathrm{H}\right)$ are released during processing, and some of the semi-volatile fission products ( $C s$ and Ru) are released during pellet sintering. Medium-and low-volatility fission products 
( $\mathrm{Ba}, \mathrm{Sr}, \mathrm{Ce}, \mathrm{La}, \mathrm{Pd}, \mathrm{Zr}$ ) remain in the fuel, as do the uranium, plutonium, and actinides.

The fuel that remains after the AIROX processing contains approximately $1.4 \%$ fissile material, depending on the burnup and initial enrichment. The fuel recycling concept is that this fuel can be further enriched (if necessary), pelletized, fabricated into fuel rods, and recycled to the reactor. For CANDU reactors, which normally use natural uranium as the fuel, the AIROX-processed fuel, even without additional enrichment, has plenty of fissile materials left for excellent utilization. For use in light water reactors (LWRs), the AIROX-processed fuel must be blended with additional ${ }^{235} U$ or ${ }^{239} \mathrm{Pu}$. AIROX-processed fuel can also be used in fast breeder reactors, depending on the mission to be accomplished. With new cladding for the fuel, there appears to be no serious technical problems for this concept.

In this study, we have considered two technical issues involved in use of this fuel in a LWR. First, we addressed core neutronics and safety issues. Are there any obvious critical safety issues that would prohibit use of this fuel in a reactor? Second, we addressed the question of waste management. How would this concept affect total spent fuel waste management for the U.S.?

We envision AIROX recycling serving several possible functions:

- AIROX recycling could provide a better utilization of fissile contents of fuel by recycling spent fuel back to reactors.

- Nuclear spent fuel generated per kWe would be reduced.

- Uranium and plutonium from weapons material could be expended by using them to enrich the recycled fuel.

- AIROX recycling could provide flexibility in spent fuel management. The fuel would stay in the recycling mode for a longer period of time, providing more time for the repository. 
- In the longer term, AIROX recycling would generate new alternatives for commercial high level waste disposal. AIROX could act as a front-end process for partitioning of radionuclides in the spent fuel. This process could eventually lead to partitioning of wastes and facilitate alternate disposal possibilities for radionuclides with different radiological characteristics. Long-lived fission products and actinides could be disposed in a repository, while shorter-Tived radionuclides could be stored at or near surface until decay reduces activity to harmless levels. Research directed at spent fuel recycling and new high-level waste partitioning technologies could minimize or eliminate current barriers to public acceptance of nuclear power.

There is one drawback to this scheme. Because of the presence of residual fission products in the recycled fuel, the entire process must be handled remotely, resulting in more difficult fuel inspection and additional equipment for new fuel handling.

\subsection{International Interest in Dry Processing and Recycling of SPEnt fuel}

Significant activities are underway in this area in other countries. The Canadians have determined that a synergistic CANDU-LWR fuel cycle is highly beneficial. ${ }^{1-3,1-4}$ Although CANDU reactors use natural uranium, slightly enriched uranium (SEU), in the range of $0.9-1.5 \mathrm{wt} . \%{ }^{235} \mathrm{U}$, is economically attractive in today's environment. ${ }^{1.3}$ This offers a $20-30 \%$ reduction in the cost of the once-through fuel cycle and a similar improvement in resource utilization. Atomic Energy Canada Limited $(A E C L)^{1-5}$ has investigated various options for fuel management for this LWR-CANDU synergism and has concluded that the AIROX (which they call OREOX) process is a top candidate for this cycle.

South Korea has both pressurized water reactors (PWRs) and CANDU reactors. The potential for reusing the spent fuel from PWRs in the CANDU reactors is of major importance to the Koreans. Canada and Korea are working 
together to develop advanced fuel cycles where PWR spent fuel is used in CANDUs. $^{1-6}$ The Koreans are already manufacturing CANDU fuel in Korea. Koreans are committed to maximizing fuel utilization in their strong indigenous nuclear power program. This is part of their phitosophy of recycling and reutilization to become self-sufficient in energy and achieve security in energy supply.

AECL, Korea Atomic Energy Research Institute (KAERI), and the U.S. State Department have signed an agreement to perform research work for the Direct Use of Spent PWR Fuel in CANDUs (DUPIC). This will explore the AIROX recycling method for the LWR-CANDU fuel cycle. The LOS Alamos National Laboratory (LANL) has performed safeguards analysis for this cycle. The Phase 1 part of the KAERI/AECL study was completed in 1.992 and a Phase 2 demonstration program is now being planned.

H. Kusters et al. ${ }^{1.7}$ in Germany have investigated multiple recycling of nuclear waste in PWRs. They were interested in actinide and fission product recycling (AFR) and considered the dry refabrication technique of the AIROX. process. They found that the AFR schemes do not lead to a practical reduction of hazards. They have argued that since all actinides are recycled, and since isotopes with high mass numbers above Am have large hazard indices, the accumulation of these products in the recycled spent fuel will increase its hazard potential. They have not addressed the problem from an overall waste management perspective. They recommend that new industrial scale separation techniques be developed that will allow separation of individual actinides; then one would not recycle $\mathrm{Cm}$ and other actinides with even higher mass numbers. They have also expressed concern about the additional handling problems that would be necessary for this process for both fuel transportation and refabrication.

In Japan, the program Options Making Extra Gains from Actinides and fission products (OMEGA) is most noteworthy..$^{1-8}$ It is Japan's long-term program for high-level waste management and concentrates on research and development work on nuclide partitioning and transmutation. The philosophy of this program is, first, to utilize all materials in the spent fuel that can be 
used, namely the fissile materials, uranium and plutonium, and other recoverable useful metals (e.g., platinum). High-level waste resulting from initial separation will then be partitioned, transmuted, and utilized or disposed. All potential concepts of reactors and accelerators are being investigated to achieve these goals. Dry processing techniques such as AIROX are being investigated for partitioning transuranic elements and fission products.

\subsection{Safeguards Issues}

Application of the AIROX process for LWR recycling requires reenrichment. This calls for an examination of this concept from a nonproliferation point of view. The safeguards issues of recycling LWR fuel into CANDU reactors have been examined by the LoS Alamos National Laboratory. ${ }^{1-5}$ According to this study, the DUPIC fuel cycle is relatively proliferation resistant because (a) the fuel cycle does not involve any fissile material in pure form; (b) the AIROX process does not entail aqueous processing and does not produce pure or partially pure plutonium products; and (c) the fission products retained in the fuel make the reconstitution process a highly automated operation in canyons or highly shielded cells that will act as containment. Finally, the change in special nuclear material in going from PWR spent fuel to a CANDU reactor fuel bundle is such that there is almost no net increase in diversion potential of the fissile material.

AIROX-recycled fuel for use in LWRs requires re-enrichment to about $4 \%$. Re-enrichment of AIROX fuel can be done with different blending powders. For example, available weapons materials or $17 \%$ enriched uranium powder could be utilized. Safeguarding of the new fissile material to be added to the product must be assured. Use of pure fissile material would be highly beneficial from a waste-management perspective, since it would utilize more of the AIROX fuel and deplete the available wapons material. However, safeguarding procedures, including security forces needed for the facility, would add considerably to the fuel fabrication cost. Safeguards issues could be reduced by using a lower enriched fissile material for recycling LWR spent fuel. From this point of view, use of less than $20 \%$ enriched material may be recommended, because 
more than $20 \%$ enriched fissile material is considered potential weapons material by both International Atomic Energy. Agency and U.S. standards. The dilution of the weapons material could be done by the defense sector or at defense national laboratories with relative ease.

\subsection{Report ORganization}

The details of the AIROX process and what has been done in the past are described in Section 2. This section discusses the necessary chemical engineering processes needed to carry out an AIROX unit operation. Facilities and sequential operations needed to process spent fuels are described. The material balance and the amount of wastes that will be generated in such a facility are enumerated. The cost of constructing and operating a $500 \mathrm{MT} /$ year AIROX recycling facility has been estimated. Finally, Section 2 deals with the research and development work that must be done to support commercial demonstration of the AIROX process. This includes a wide variety of subjects, from new ideas for cladding removal to recovery of volatile gases.

Section 3 deals with the fuel management aspects of using the AIROX fuel in an LWR. Results from several reactivity calculations are presented to assure us that the recycled fuel, with some additional enrichment, can be used in a typical LWR reactor. The limitations are also discussed. It is found that the poisoning effects of the left-over fission products can be overcome. The power peaking in adjacent fresh assemblies presents some problems, and this needs to be addressed in future studies. From our understanding of highburnup fuel performance, we do not foresee a significant problem in using AIROX fuel in a LWR, at least for a reasonable burnup. However, some more studies should be performed for high burnup of AlROX fuel. The areas of research in this area are also elaborated.

Section 4 investigates the waste management aspects of AIROX recycling. First, the amount of different wastes that will be generated are estimated, with reasonable assumptions; and disposition of these wastes are discussed. Since heat loading from spent fuel is a significant parameter for repository design, we have estimated the amount of heat loading expected from recycled 
spent fuel. As expected, because of the presence of additional fission products and the actinides, the AIROX-recycled fuel will have higher heat loadings on a per metric ton of initial heavy metal (MTIHM) basis. However, this may not be a significant problem when the total amount of electricity generation is taken into account.

Section 4 also presents an evaluation of the impact of AIROX recycling on the U.S. commercial high level waste volumes. The model considered two scenarios taken from the U.S. Department of Energy's (DOEs) National Energy Strategy (NES) $)^{1.9}$ and the resulting projections for spent nuclear fuel. It was found that for the no-nuclear-growth option, AIROX will reduce the total highlevel waste by about 10\%. However, for the nuclear-growth scenario of the NES, AIROX-recycling implementation could reduce high-level waste volume by about $30 \%$.

Finally, Section 5 addresses the AIROX recycling concept and its potential impact on nuclear energy revitalization in the U.S. It discusses the advantages and the problems associated with this technology. It also elaborates on the areas of research and development that would be needed to commercialize the AIROX recycling program in the United States.

There are several people and organizations that have contributed to this report. Westinghouse Idaho Nuclear Company (WINCO) and EG\&G idaho, Inc, were the primary organizations for this work at the INEL. The Rockwell International (RI) and Westinghouse Hanford Company (WHC) participated in this work at the INEL through a subcontract with WINCO. WINCO and RI have performed the studies on the prototypical AIROX facility, while WHC developed the ITHINK model for AIROX impact studies for the U.S. high-level waste. In general, WINCO investigated the AIROX process, its facilities and operations, and the amount of wastes generated by the AIROX process. EG\&G Idaho investigated the feasibility of using the recycled fuel in LWRs.

\subsection{References}

1-1. L. Leach et al., "Waste Minimization: An Important Element in the Revitalization of the Nuclear Power Industry," Proceedings of the 
International Conference, Spectrum 92: Nuclear and Hazardous Waste Management, Boise, ID, August 23-27, 1992.

1-2. L. F. Grantham et a1., AIROX Dry Pyrochemical Processing of Oxide Fuels: a Proliferation-Resistant Reprocessing Method, Rockwell International report, 1980; also in Am. Chem. Soc. Symposium Series 117, 219, 1980.

1-3. I. J. Hastings et a1., "Synergistic CANDU-LWR Cycles", 6th Korea Atomic Industrial Forum/Korea Nuclear Society Joint Annual Conference, Seoul, Korea, Apri7 15-17, 1991.

1-4. P.G. Boczar, I.J. Hastings, and A. Celli, Recycling in CANDU of Uranium and/or Plutonium from Spent LWR Fuel, AECL-10018, November 1989.

1-5. J.-S. Hong, K. K. S. Pillay, and E. Payne, "Safeguards Issues of the Direct Use of Spent PWR Fuels in CANDU Reactors," Transactions of the American Nuclear Society, 66, 129, 1992.

1-6. R. Doust, "Canadian-Korean Partnership Works Towards a Tandem Fuel Cycle", Nuclear Engineering International, April 1992, p. 36.

1-7. H. Kusters et al., "Recent Investigations in France and Germany on the Transmutation of Actinides and Fission Products in Reactors," Proceedings of the International Conference on Design and Safety of Advanced Nuclear Power Plants, Tokyo, Japan, October 25-29, 1992, p. 5.3-1.

1-8. S. Hoshiba et al., "Progress of the OMEGA Program in Japan," Transactions of the American Nuclear Society, 64, 108, 1991.

1-9. U.S. Department of Energy, National Energy Strategy, DOE/S-00828, 1991. 


\section{THE AIROX PROCESS}

The AIROX process is a dry method for recycling LWR spent nuclear fuel. It involves pulling the fuel rods from the fuel assembly, puncturing the cladding of each fuel rod at about $2.5 \mathrm{~cm}$ intervals, and exposing the fuel rods to multiple high-temperature cycles of $\mathrm{O}_{2}$ and $\mathrm{H}_{2}$. This converts the $\mathrm{UO}_{2}$ to a powder via the $\mathrm{UO}_{2} \leftrightarrow \mathrm{U}_{3} \mathrm{O}_{8}$ reaction and volatizes some fission products. The $\mathrm{UO}_{2}$ powder is then mechanically separated from the cladding, ground to less than $10 \mu \mathrm{m}$, and blended with highly enriched uranium/plutonium oxide powders. The enriched $\mathrm{UO}_{2}$ powder is then repelletized and sintered for loading into reconstituted fuel rods and assemblies.

The AIROX process was conceived as a dry, low-decontamination process that would be simpler than aqueous reprocessing schemes by retaining most of the fission product inventory in the recycled and reconstituted fuel assemblies. The dry processing scheme would avoid the generation of highlevel liquid waste streams, recycle the fertile ${ }^{238} \mathrm{U}$, and, in principle, allow extended burnup to about $120 \mathrm{MWd} / \mathrm{kgU}$ via three or four recycles.

Pulverization of the $\mathrm{UO}_{2}$ pellets takes place by oxidation with $\mathrm{O}_{2}$ in argon at about $400^{\circ} \mathrm{C}$, which expands the fuel volume by about $30 \%$ while forming the higher oxide. The volume increase ruptures the cladding and putverizes the fuel. The $\mathrm{U}_{3} \mathrm{O}_{8}$ is reduced back to $\mathrm{UO}_{2}$ with dilute hydrogen $(10 \%-20 \%)$ in argon at about $600^{\circ} \mathrm{C}$. Up to three oxidation-reduction cycles are used to achieve the desired particle size distribution. The status of work done to date is discussed below.

\subsection{Prior AiroX Studies}

Most of the experimental work on the AIROX process was performed by Atomics International $7^{2 \cdot 1}$ to $2 \cdot 8$ between 1959 and 1965. Kilogram-scale cold experiments were performed on unirradiated $\mathrm{UO}_{2}$, both with and without simulated fission products; $;^{2-2.3,4}$ and small-scale hot experiments were conducted on $100 \mathrm{~g}$ pellets with burnups to $31 \mathrm{MWd} / \mathrm{kg} \cdot{ }^{2-5,6}$ 
Two of the initial concerns addressed were the effects of fission product buildup and multiple recycle on the rates of oxidation and reduction during the puiverization step and the ability to obtain near theoretical density of $\mathrm{UO}_{2}$ pellets in the sintering step. Cold studies were conducted on $\mathrm{UO}_{2}$ pellets in which oxides of stable isotopes (Ba, Ce, Cs, La, Mo, Nb, Nd, Pr, Ru, Sm, $\mathrm{Sr}, \mathrm{Y}$, and $\mathrm{Zr}$ ) were added prior to pelletizing to simulate $20-\mathrm{MWd} / \mathrm{kg}$ burnup for each recycle. ${ }^{2-4}$ During each AIROX recycle, the pellets were exposed to three oxidation-reduction cycles. The AIROX recycle process was repeated five times to simulate an accumulative burnup of $100 \mathrm{MWd} / \mathrm{kg}$. Experimental results indicated that simulated high burnup and multiple recycle did not significantly affect the pulverization of the $\mathrm{UO}_{2}$ pellets and appeared to enhance pellet sintering, since higher pellet densities were achieved in recycles 3, 4, and 5 (98\%-100\% of theoretical) than in recycles 1 and 2 (91\%93\% of theoretical).

Cold small-scale decladding experiments were conducted on 10 - to $15-\mathrm{cm}$ sections of $\mathrm{UO}_{2}$ pellets $\mathrm{clad}$ in stainless steel and zircaloy tubes, which demonstrated the feasibility of this step of the AIROX process. ${ }^{2-1}$ Cold scaled-up experiments were conducted on $28-$ to $91-\mathrm{cm}$ sections of $\mathrm{UO}_{2}$ pellets in stainless steel cladding. ${ }^{2-7}$ These experiments indicated that a fuel rod punctured at $2.5-\mathrm{cm}$ intervals and exposed to oxygen at $4.00^{\circ} \mathrm{C}$ for two hours would be completely decladded. Repetitious cycling of the oxidation/reduction steps provided up to $99.9 \%$ mechanical separation of the fuel from the cladding. ${ }^{2-9}$ All of the powder formed is under $2000 \mu \mathrm{m}$, with a progressively smaller size distribution after each oxidation/reduction cycle. After the first and second cycle, 55\% and 93\%, respectively, of the powder is in the 10 to $74-\mu m$ size range. ${ }^{2-10}$

The AIROX process was tested on spent fuels with burnups of $5.7,18$, and $21 \mathrm{MWd} / \mathrm{kg}$, respectively. The spent fuels were remotely processed using three oxidation-reduction cycles..$^{2-5} \mathrm{UO}_{2}$ pellets (about $88 \mathrm{~g}$ for each burnup history) were reconstituted from the spent fuel powder for insertion into three $20-\mathrm{cm}$ stainless steel irradiation capsules. ${ }^{2-6}$ The reconstituted $\mathrm{UO}_{2}$ pellets were irradiated an additional $10 \mathrm{MWd} / \mathrm{kg}$, then remotely AIROX-processed and pelletized again. ${ }^{2-8}$ The hot tests indicated that the oxidation, 
reduction, and decladding rates for irradiated $\mathrm{UO}_{2}$ pellets are similar to unirradiated $\mathrm{UO}_{2}$ pellets.

The hot tests also indicated that all of the volatile fission products (i.e., tritium, ${ }^{85} \mathrm{Kr}$, and ${ }^{129} \mathrm{I}$ ) would be released during the multiple cycles of oxidation and reduction, and large fractions of semi-volatile fission products (e.g., up to $95 \%$ of the ${ }^{137} \mathrm{Cs}$ and $50 \%$ of the ${ }^{108} \mathrm{Ru}$ ) would be released during the pellet sintering step. ${ }^{2-9}$ Smaller amounts of tellurium, technetium, cadmium, and indium are also volatilized during the pellet sintering step.

\subsection{Chemical Engineering Concepts}

The systems analysis approach used to model the potential impact of AIROX recycling on the generation rates of spent nuclear commercial fuel (see Section 4.3) required that a set of ground rules and assumptions be used as part of the AIROX facility design criteria. The amount and type of radioactive waste generated by the AIROX facility were based on the groundrule assumptions.

Figure 2-1 illustrates some of the assumed process steps and types of wastes generated. One of the first unit operations would be to receive, assay for fissile content, and disassemble the fuel assembly. Holes would then be mechanically punched down the length of the pin. The unit operations depicted down the center of Figure 2-1 are: (a) pulverization and decladding with al ternate cycles of $\mathrm{O}_{2}$ at about $400^{\circ} \mathrm{C}$ and $\mathrm{H}_{2}$ at about $600^{\circ} \mathrm{C}$; (b) ball milling the powder to $10 \mu \mathrm{m}$ and mixing in virgin enriched $\mathrm{UO}_{2}$ powder; (c) pelletizing the powder; (d) sintering the pellets at about $1700^{\circ} \mathrm{C}$; (e) machining the pellets; ( $f$ ) fabricating the fuel pins; ( $g$ ) fabricating the fuel assembly; and (h) inspecting and certifying the fuel assembly for return to the reactor.

The assumec types of waste forms generated are as follows. Spent hardware and cladding would be greater than Class C (GTCC) waste, due to the presence of activation products $\left({ }^{59} \mathrm{Ni},{ }^{63} \mathrm{Ni}\right.$, and $\left.{ }^{94} \mathrm{Nb}\right)$, and would be crushed (volume reduced) and/or melted into ingots for disposal. Recovered ${ }^{129} \mathrm{I}$ would 


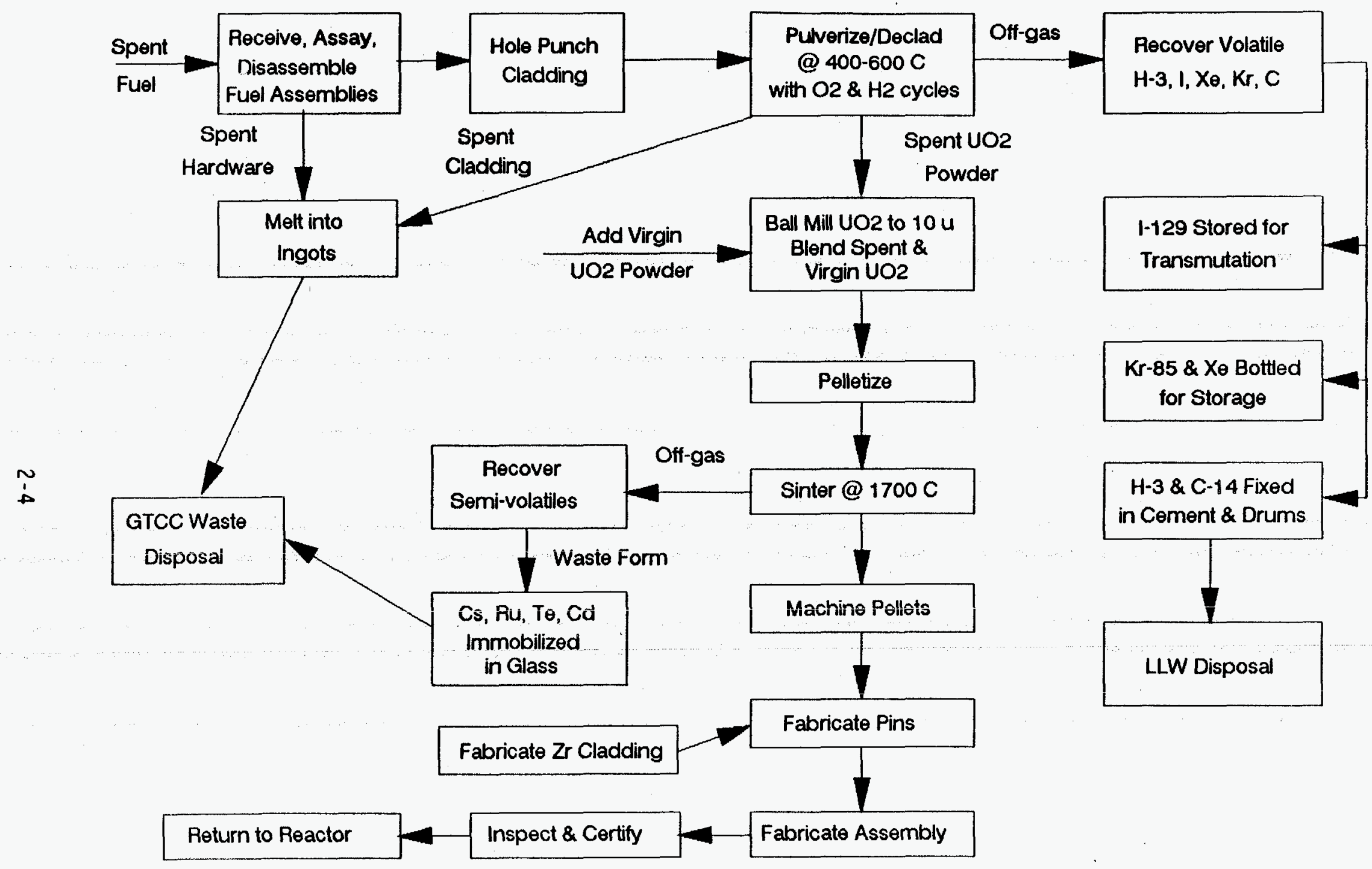

Figure 2-1. Unit operations in the AIROX process. 
be stored for future transmutation. Recovered noble gas fission products would be bottled and placed in storage. Recovered tritium and ${ }^{14} \mathrm{C}$. would be combined and immobilized in cement as low level waste (LLW). Recovered semivolatiles would be immobilized together in a borosilicate glass-waste form for GTCC waste disposal. All of the spent $\mathrm{UO}_{2}$ was assumed to be recycled and reconstituted in the process.

\subsubsection{AIROX Process Waste Generation Rates}

To estimate spent fuel radionuclide inventories and rates of LLW and GTCC wastes generated in a prototypical AIROX facility, several simplifying assumptions were made:

- Spent fuel receipts would be a mix of $67 \%$ PWR and $33 \%$ BWR fuels, which is the nominal mix of spent fuel in U.S. storage.

- The Westinghouse $17 \times 17$ assembly and the Exxon/ANF $7 \times 7$ assembly were assumed as reference assemblies for PWR and BWR fuel, respectively.

- All once-through reactor spent fuel would be cooled for 5 years with burnups of $33 \mathrm{MWd} / \mathrm{kg}$ of initial heavy metal for PWR fuel and 27.5 MWd/kg for BWR fuel.

- For each recycle, the spent fuel would have accrued an additional burnup of $33 \mathrm{MWd} / \mathrm{kg}$ of initial heavy metal for PWR use and 27.5 MWd/kg for BWR use. Cooling time for recycled fuel would also be 5 years.

- All spent $\mathrm{UO}_{2}$ would be recycled to avoid generation of high-level waste (HLW).

- $100 \%$ of the fuel inventory's volatile radionuclides (tritium, krypton, xenon, iodine, and carbon) would be volatilized during the decladding step. 
- $90 \%$ of the fuel inventory's semi-volatile radionuclides $\left({ }^{134} \mathrm{Cs}\right.$, ${ }^{137} \mathrm{Cs}$, and ${ }^{106} \mathrm{Ru}$ ) and $75 \%$ of the tellurium, cadmium, and indium wourd be volatilized during the pellet sintering step.

- All of the recovered semi-volatiles would be immobilized together in a glass waste form, and glass loading would be dictated by heat load from the ${ }^{134 / 137} \mathrm{Cs}$ isotopes.

Table 2-1 lists the waste generation rates and radioactive decay heat loads per MTIHM of spent fuel processed via AIROX using the above assumptions. The spent fuel radionuclide and heat contents are based on data in the 1988 ORNL database for spent commercial nuclear fuel. ${ }^{2 \cdot 11}$ Constraints on radionuclide waste form loadings are given in Table 2-1 or the footnotes. The cladding and hardware GTCC wastes generated were calculated to be 0.29 MT/MTIHM processed based on fuel assembly data given in the 1988 ORNL database for the reference fuel assemblies. Melting the cladding and hardware into ingots would result in about $0.045 \mathrm{~m}^{3} /$ MTIHM, assuming a density of $6.5 \mathrm{~g} / \mathrm{cc}$ for zirconium.

\subsubsection{Prototypical AIROX Facility}

The preconceptual design of a prototypical AIROX facility used for process description and cost analysis was prepared and issued by the Rocketdyne Division of Rockwell International. ${ }^{2-12}$ The plant design was based on a reprocessing capacity of $200 \mathrm{MTIHM} / \mathrm{year}$. The plant would be designed to perform the remote unit operations illustrated in Figure 2-1. The plant was assumed to operate 221 days a year at a full processing capability of 0.9 MTIHM/day. Downtimes included allowances for periodic plant maintenance, accountability, programmed start up and shutdown, and unanticipated process upsets. Based on the weight of uranium used in standard PWR and BWR assemblies $(0.4636 \text { and } 0.183 \mathrm{MT} \text {, respectively) })^{3.11}$ and the assumed mix of $86.5 \%$ spent and $13.5 \%$ virgin $\mathrm{UO}_{2}$, the production rate of new PWR and BWR assemblies would be 1.5 and 1.8 assemblies/day, respectively. 
Table 2-1. Amounts of LLW and GTCC wastes and stored fission products generated per MT of spent fuel processed via AIROX.

\begin{tabular}{|c|c|c|c|c|c|c|c|c|}
\hline $\begin{array}{l}\text { Fission product } \\
\text { radionuclide }\end{array}$ & $\begin{array}{c}t_{1 / 2} \\
\text { (years) }\end{array}$ & $\begin{array}{l}\text { Activity } \\
(\mathrm{g} / \mathrm{C} i)\end{array}$ & \multicolumn{2}{|c|}{$\begin{array}{l}\text { Fuel inventory } \\
(\mathrm{Ci} / \mathrm{MT})(\mathrm{g} / \mathrm{MT})\end{array}$} & $\begin{array}{l}\% \text { removed } \\
\text { from fue } 1 \\
\end{array}$ & $\begin{array}{l}\text { Heat content } \\
\text { (W/MT) }\end{array}$ & Assumed waste form & $\begin{array}{l}\text { Amount of waste per } \\
\text { MT of fuel processed }\end{array}$ \\
\hline${ }^{3} \mathrm{H}$ & 12.3 & $1.04 E-4$ & 586 & 0.061 & 100 & 0.0067 & $\begin{array}{l}\text { HTO in cement. LLW loading } \\
\text { limits not given }\end{array}$ & $\begin{array}{l}0.36 \mathrm{ml} \text { of HTO in drums } \\
\text { combined with }{ }^{14} \mathrm{C}\end{array}$ \\
\hline${ }^{14} C^{d}$ & 5730 & 0.225 & 1.53 & 0.34 & 100 & nil & $\begin{array}{l}\mathrm{BaCO}_{3} \text { in cement with } \mathrm{LLW} \\
\text { loading of }<8 \mathrm{Ci} / \mathrm{m}^{3}\end{array}$ & $\begin{array}{l}0.19 \mathrm{~m}^{3} \text { or nearly one } \\
\text { waste drum }\left(0.21 \mathrm{~m}^{3}\right)\end{array}$ \\
\hline${ }^{83} \mathrm{Kr} \cdot{ }^{84} \mathrm{Kr},{ }^{86} \mathrm{Kr}$ & $\begin{array}{l}10.7 \\
\text { Stable } \\
\text { Stable }\end{array}$ & $\begin{array}{c}0.00255 \\
-- \\
--\end{array}$ & $\begin{array}{c}6284 \\
-- \\
--\end{array}$ & $\begin{array}{c}16 \\
340 \\
5012\end{array}$ & $\begin{array}{l}100 \\
100 \\
100\end{array}$ & $\begin{array}{l}9.4 \\
-- \\
--\end{array}$ & $\begin{array}{l}\text { Standard USA cylinder is } \\
50 \mathrm{~L} 034 \mathrm{~atm} \& 60^{\circ} \mathrm{C} \text { which } \\
\text { equate to } 62 \mathrm{moles} \text { of gas; } \\
\text { limit of } 1.28 \mathrm{C} 5 \mathrm{Ci}^{\circ}\end{array}$ & $\begin{array}{l}\text { Bott le both krypton and } \\
\text { xenon fission products } \\
\text { to produce } 0.66 \text { cylinder } \\
\text { and placed in storage }\end{array}$ \\
\hline${ }^{129} \mathrm{I}$ & $\begin{array}{r}1.6 E 7 \\
\text { Stable }\end{array}$ & $\begin{array}{c}5671 \\
\cdots\end{array}$ & 0.0298 & $\begin{array}{r}169 \\
52\end{array}$ & $\begin{array}{l}100 \\
100\end{array}$ & nil & $\begin{array}{l}\text { Recovered and stored on } \\
\text { silver-zeolites } 0.18 \mathrm{~g} \\
\text { of iodine/cc of zeolite } \\
\end{array}$ & $\begin{array}{l}1.23 \mathrm{~L} \text { of iodine-loaded } \\
\text { zeolite stored for } \\
\text { transmutation }\end{array}$ \\
\hline $\begin{array}{l}{ }^{137} \mathrm{Cs} \\
{ }^{136} \mathrm{Cs} \\
{ }^{135} \mathrm{Cs} \\
{ }^{134} \mathrm{Cs} \\
{ }^{133} \mathrm{Cs}\end{array}$ & $\begin{array}{l}30 \\
2.05 \\
3 E 6 \\
\text { Stable }\end{array}$ & $\begin{array}{l}0.0115 \\
0.00077 \\
868 \\
--\end{array}$ & $\begin{array}{c}8.7 \mathrm{E} 4 \\
2.5 \mathrm{E} 4 \\
0.35 \\
--\end{array}$ & $\begin{array}{r}1000 \\
20 \\
304 \\
1072\end{array}$ & $\begin{array}{l}90 \\
90 \\
90 \\
90\end{array}$ & $\begin{array}{r}86 \\
232 \\
\mathrm{nil} \\
--\end{array}$ & $\begin{array}{l}\text { Immobilized in glass as } \\
\text { GTCC waste: Assume heat } \\
\text { load } 1 \text { imit of } 5200 \\
\text { watts } / \text { canister with } \\
0.63 \mathrm{~m}^{3} \text { capacity }\end{array}$ & $\begin{array}{l}0.061 \text { canister which } \\
\text { equals } 0.038 \mathrm{~m}^{3} \text { of glass } \\
\text { or } 0.103 \text { MT of glass at } \\
\text { a density of } 2.7 \mathrm{~g} / \mathrm{cc}\end{array}$ \\
\hline $\begin{array}{l}{ }^{106} \mathrm{Ru} \\
{ }^{101} \mathrm{Ru} \\
{ }^{102} \mathrm{Ru} \\
{ }^{104} \mathrm{Ru}\end{array}$ & $\begin{array}{c}1.0 \\
\text { Stable }\end{array}$ & 0.0003 & $\begin{array}{l}1.58 \mathrm{E} 4 \\
--\end{array}$ & $\begin{array}{r}4.7 \\
2040\end{array}$ & $\begin{array}{l}90 \\
90\end{array}$ & $\begin{array}{c}0.84 \\
--\end{array}$ & $\begin{array}{l}\text { Combine with Cs in glass } \\
\text { GTCC waste; impact insig- } \\
\text { nif icant on heat load }\end{array}$ & $\begin{array}{l}\text { No increase in waste } \\
\text { volume over Cs wastes }\end{array}$ \\
\hline Cd, Te, \& In $^{t}$ & -- & - & 816 & 412 & 75 & 0.71 & $\begin{array}{l}\text { Combine with Cs in glass } \\
\text { GTCC waste; impact insig- } \\
\text { nificant on heat load }\end{array}$ & $\begin{array}{l}\text { No increase in waste } \\
\text { volume over Cs wastes }\end{array}$ \\
\hline
\end{tabular}

a. Radionuclide inventory in one MT of 5 -yr cooled spent fue 7 (67\% PWR + 33\% BWR mix with burnups of 33 and 27.5 MWd/kg, respect ively).

b. Heat content of the \% of radionuclide inventory removed from one MT of spent fuel.

c. No waste limits are given for ${ }^{3} \mathrm{H}$ in $10 \mathrm{CFR} 61$ (Licensing Requirements for Land Disposal of Radioactive Waste).

d. ${ }^{14} \mathrm{C}$ is a neutron activation product formed from ${ }^{12} \mathrm{C}$ impurities in the fue 1 matrix.

e. IAEA Technical Report Series No. 199, p 42 (1980).

f. These semi-volatiles are lumped because heat load is insignificant compared to ${ }^{134} \mathrm{Cs}$ and ${ }^{137} \mathrm{Cs}$; mass load of Cs, Ru, Cd, Te, \& In less than $5 \%$ wt of glass. 
Assumed separation of the spent fuel from the cladding after exposure to the $\mathrm{O}_{2}$ and $\mathrm{H}_{2}$ cycles would depend on the type of process chosen. For mechanical separation, $95 \%$ fuel recovery is assumed. For solvent washing, $99.5 \%$ fuel recovery is assumed. For acid leaching, $100 \%$ fuel recovery is assumed.

The off-gas treatment system for recovery of volatile and semi-volatile radionuclides and the sequence of the removal steps were not established for this study. However, low off-gas flow rates and the use of argon as the carrier gas would be highly advantageous for designing a customized off-gas cleanup system. Conceptualiy, the removal could be performed as follows:

- Semi-volatile radionuclides could be removed by high-temperature sintered metal filters, followed by high-temperature HEPA filters.

- Volatile radionuclides $\left({ }^{3} \mathrm{H}, \mathrm{CO}_{2}, \mathrm{I}_{2}, \mathrm{Xe}, \mathrm{Kr}\right)$ could be passed over a high-temperature oxidative catalyst to form HTO, which could be passed over a heated bed of barium hydroxide-octahydrate, to form adsorbed HTO and chemisorbed barium carbonate.

- The remaining $I_{2}, X e$, and $K r$ could be passed over a heated bed of silver-impregnated zeolite to remove iodine as chemisorbed silver iodide or iodate.

- The remaining $\mathrm{Xe}$ and $\mathrm{Kr}$ could be passed through a cryogenic distillation unit to condense them from the argon carrier gas.

The spent fuel assemblies shipped to the $p l$ ant were assumed to contain a residual enrichment of $1.4 \%$ (i.e., $0.8 \%{ }^{235} \mathrm{U}$ and $0.6 \%{ }^{239} \mathrm{Pu}$ ). The virgin makeup fuel material was assumed to be $17 \%$ enriched and in powder form suitable for addition to the spent powder. The nominal mix of the reconstituted fuel would contain about $86.5 \%$ spent fuel powder and $13.5 \%$ virgin powder, which would result in an incremental enrichment of $2 \%$ and total enrichment of $3.5 \%$ for the first recycled fuel. Subsequent recycled fuels would contain progressively higher amounts of residual fissile content, but 
the incremental additive enrichment would remain at about $2 \%$ for each additional recycle.

As indicated in Table 2-1, about 1 drum of $L L W$ containing ${ }^{3} \mathrm{H}$ and ${ }^{14} \mathrm{C}$ per MTIHM processed would be generated from the process off-gases. In addition to this, Rocketdyne estimates that secondary LLW from plant activities (i.e., laboratory waste, decontamination activities, spent filters, solid wastes, replaced process equipment, and so on) would generate an additional 9 drums $\left(1.89 \mathrm{~m}^{3}\right)$ of LLW/MTIHM processed. ${ }^{2-12}$

The proposed AIROX reprocessing facility consists of a three-story building, with a floorspace of $4330 \mathrm{~m}^{2}$ for each story. The fuel reprocessing level is $10.7 \mathrm{~m}$ below grade, and the roof of the facility is $12.4 \mathrm{~m}$ above grade. Activities on this level include receiving, storing, and shipping of spent and new fuel; fuel decladding and AIROX processing; new fuel fabrication; and certain building services. Receiving and shipping of spent and new fuel is assumed to be by truck.

Fuel transfer from the storage racks would be done through an airlock to an inert-atmosphere (argon) cell in which the fuel is disassembled, AIROXprocessed, enriched in fissile isotopes, and mixed with a binder and die lubricant. The atmosphere in this cell would be inert to prevent oxidation of the $\mathrm{UO}_{2}$ and to facilitate removal of radioactive fission gases from the cell atmosphere. The sinterable powder product would be stored in containers prior to transfer to the cells where new fuel assemblies would be fabricated.

The second level (ground floor) would contain the change rooms, support services (offices, radiation safety, security, electrical, machine shop, maintenance, janitorial), radioactive equipment decontamination and maintenance areas, limited highly radioactive waste processing equipment, and most of the LLW processing equipment. The third level would contain heating and ventilation systems, some LLW processing, and various process and building services. 


\subsection{AIROX COST Estimates}

The preconceptual AIROX facility design also included cost estimates. 2-12 For building first-of-a kind and nth-of-kind 500 MTIHM/y plants, Rocketdyne estimated capital costs of $\$ 850$ and $\$ 500$ million (M), respectively. Annual operating costs of staff, consumables, utilities, and waste disposal were estimated at $\$ 165 \mathrm{M} / \mathrm{y}$. This does not include the cost for purchase of uranium to enrich the spent fuel, which would add an additional $\$ 200 \mathrm{M} /$ year at current market prices. Not included were costs associated with recovery of capital investment, profit, insurance, taxes, and a fund for eventual decommissioning and decontamination of the facility. Some assumed economic assumptions use for these estimates include:

- The capital cost of $500 \mathrm{MT} / \mathrm{y}$ plant was scaled up from the estimate for a $200 \mathrm{MT} / \mathrm{y}$ plant by the ratio of the two plant sizes raised to the 0.6 power:

Capital $\operatorname{Cost}(500 \mathrm{Mt} / \mathrm{y})=$ Capital $\operatorname{Cost}(200 \mathrm{MT} / \mathrm{y}) \times[500 / 200]^{0.6}$

- The annual operating cost for staffing a $500 \mathrm{MT} / \mathrm{y}$ plant was scaled up from the estimate for a $200 \mathrm{MT} / \mathrm{yr}$ plant by the ratio of the two plant sizes raised to the 0.6 power, while consumables (mainly enriched uranium costs) were directly proportional to plant size:

Staffing $\operatorname{Cost}(500 \mathrm{MT} / \mathrm{y})=$ Staffing $\operatorname{Cost}(200 \mathrm{MT} / \mathrm{y}) \times[500 / 200]^{0.6}$ Consumable $\operatorname{Cost}(500 \mathrm{MT} / \mathrm{y})=$ Consumable $\operatorname{Cost}(200 \mathrm{MT} / \mathrm{y}) \times[500 / 200]$

- Round-the-clock operation requires five shifts--four operating shifts and one shift in training, with a total staffing of 780 workers.

- Equipment replacement costs are $10 \%$ of the capital cost per year.

- PWR and BWR assembly hardware costs $\$ 58,000$ and $\$ 23,000$ per assembly, respectively. 
- The krypton/xenon gas storage bottles cost $\$ 1500$ each.

- LLW containers are $55 \mathrm{gal}\left(0.21 \mathrm{M}^{3}\right)$ drums that cost $\$ 150$ each.

- GTCC canisters cost $\$ 5000$ each.

Based on the data given in Section 2.2.1 and Table 2-1, a $500 \mathrm{MT} /$ year $\mathrm{plant}$ would generate about $145 \mathrm{MT} /$ year $\left(22.5 \mathrm{~m}^{3}\right)$ of GTCC cladding/spent hardware waste and about 51.5 MT/y of GTCC glass waste in 30.5 canisters (of $0.63 \mathrm{~m}^{3}$ capacity).

A prel iminary estimate of the break-even price for AIROX-recycled fuel assemblies has been determined by dividing the estimated annual life-cycle cost of an AIROX facility by the recycle rate. The annual life-cycle cost is estimated at $\$ 425 \mathrm{M} /$ year, based on the following assumptions:

- The capital cost of a prototype $500 \mathrm{MT} /$ year facility is $\$ 850 \mathrm{M}$. This would average out to $\$ 21 \mathrm{M} /$ year for an assumed 40 -year service life. The cost of borrowing capital to finance the original capital cost is not included.

- The annual operating cost is $\$ 365 \mathrm{M} /$ year. This includes the cost of enriched uranium and other material needed to fabricate fue 1 assemblies.

- LLW generation is 5000 drums/year, with a disposal cost of $\$ 742 /$ drum $\left(\$ 100 / \mathrm{ft}^{3}\right)$, or an annual cost of $\$ 3.7 \mathrm{M} /$ year.

- Semi-volatile fission product GTCC waste generation is 30.5 canisters/year $\left(0.63 \mathrm{~m}^{3} /\right.$ canister $)$, with a disposal cost of $\$ 350 \mathrm{~K} /$ canister, or an annual cost of $\$ 10.7 \mathrm{M} /$ year.

- A contingency fund for decontamination and decommissioning (D\&D) is set at $\$ 12.5 \mathrm{M} /$ year (to be invested over a 40 -year plant 1 ife). 
Actual D\&D costs are unknown, but they are assumed to be as much, or more, than the capital cost of plant construction.

The cost per fuel assembly needed to recover annual 1 ife-cycle costs was calculated by dividing the annual life cycle cost ( $\$ 425 \mathrm{M} /$ year) by the recycle rate (500 MT), which equates to $\$ 0.85 \mathrm{M} / \mathrm{MTIHM}$ in the fue 1 assemblies. Thus, for a standard Westinghouse $17 \times 17$ PWR fuel assembly with 0.46 MTIHM, the break-even cost would be $\$ 391 \mathrm{~K}$. For a standard Exxon/ANF $7 \times 7$ BWR fuel assembly with 0.128 MTIHM, the break-even charge would be $\$ 153 \mathrm{~K}$. This compares favorably with current nominal new fuel assembly prices. The nominal formula for estimating fuel assembly prices is $\$ 975$ per MTIHM in the fuel assembly. Based on this, the PWR assembly price would be about $\$ 450 \mathrm{~K}$ and the BWR assembly price would be about $\$ 175 \mathrm{~K}$. Therefore, using the above assumptions, the AIROX-recycled fuel prices would be competitive with new fuel assembly prices. 


\subsection{AiroX Process Research and Development Needs}

As indicated in Section 2.1, considerable cold and some hot experimental work has been done, which demonstrated the technical feasibility of the AIROX process. In this study, an assessment has been made of additional research and development work needed. These needs are discussed below in order of unit operations shown in Figure 2-1.

\subsubsection{Receive, Assay, Disassemble Fuel Assemblies}

A commercial AIROX facility would be subject to domestic safeguards procedures, which would require quantitative measurements of ${ }^{235} \mathrm{U}$ and ${ }^{239} \mathrm{Pu}$ both in the spent fuel prior to AIROX processing and in the reconstituted recycled fuel. ${ }^{2-13}$ The key measurement system for spent and refabricated fue 1 is assumed to be a non-destructive instrument. Development of non-destructive analytical instruments with sufficient accuracy to satisfy safeguards requirements would be required.

\subsubsection{Hole Punch Cladding}

In cold tests, to provide the $\mathrm{O}_{2}$ gas access to the $\mathrm{UO}_{2}$ in the fuel pin, the cladding of $91-\mathrm{cm}$ pins was mechanically punched with holes every $2.5 \mathrm{~cm}$. Test were not conducted on chopped fuel pins, because the chopping technique available at that time crimped the ends of the cladding. From a unit operations standpoint, it may be easier to handle $2.5-$ or $5-\mathrm{cm}$ sections of chopped fuel rather than full-length rods (about $400 \mathrm{~cm}$ ) during the hightemperature oxidation/reduction cycles. With the current laser cutting techniques, non-crimped cuts could be made. The relative operational complexity and costs of the two approaches should be compared conceptually.

\subsubsection{Pulverize/Declad at $400-600^{\circ} \mathrm{C}$ with $\mathrm{O}_{2} \& \mathrm{H}_{2}$ Cycles}

This is the most highly demonstrated part of the AIROX process for recycling spent fuel. Based on cold tests, there is no reason to anticipate processing problems with high-burnup materials. However, small-scale hot 
testing should be done on spent fuels recycled and irradiated 3-4 times to 100 $\mathrm{MWd} / \mathrm{kg}$ to fully demonstrate the pulverization/decladding step and al so the ability to achieve sufficient pellet densities in the sintering step.

A second issue is the need for the development of fail-safe systems to ensure that explosive mixtures of hydrogen and oxygen gases would not occur. An evaluation of an AIROX processing facility would have to assess the probability and potential consequence of an explosion. Sufficient checks and redundant safety systems (i.e., explosion proof cells, redundant oxygen and hydrogen analyzers, and so on) must be present to eliminate the potential release of the radioactive powder.

\subsubsection{Ball $\mathrm{Mill}_{\mathrm{UO}}$ to $10 \mathrm{~m}, \mathrm{Blend}$ Spent \& Virgin $\mathrm{UO}_{2}$}

Prior tests did not demonstrate the blending of virgin and spent $\mathrm{UO}_{2}$ powders. The particle distribution of the two powders would probably have to be nearly identical in order to obtain uniform mixing. This should be possible by ball-milling and sieving the powders. However, the mixing and sampling techniques to determine when the two powders are uniformly mixed have not been developed. This methodology could be developed on a cold-laboratory scale.

\subsubsection{A11 Unit Operations}

Because of the highly radioactive content of the spent fuel, all unit operations (fuel receipt and disassembly, decladding, ball milling and mixing, pelletizing, sintering, machining pellets, fabricating pins and assembly, and inspection and certification) will require remote operations. The functional requirements for mobile and fixed robots are sufficiently developed except for routine operation in a highly radioactive environment. Development of remote systems that have acceptable service 1 ife in high-radiation environments is needed. ${ }^{2 \cdot 13}$. The unit operations that involve production and handling of powder would create the additional problem of highly radioactive powders (due to dusting) coating surface components of process and robotic equipment. In 
addition to component damage from the high gamma fields, radioactive dust would cause radiation damage from beta and alpha decay.

\subsubsection{Recover Volatile ${ }^{3} \mathrm{H}, \mathrm{I}, \mathrm{Xe}, \mathrm{Kr}, \mathrm{C}$}

The off-gas cleanup technologies for these gases have been extensively developed, and detailed descriptions and reviews of the technologies have been published. ${ }^{2-14.2-15}$ As indicated in Section 2.1.2, the off-gas treatment system was not evaluated in this study. Small off-gas flows and use of argon as a carrier gas would be highly advantageous for designing an integrated off-gas cleanup system, especially for a cryogenic distillation unit. However, the key development need would be the sizing and testing of process compatibility in each step of an integrated off-gas cleanup system. In particular, the sequence of the removal steps and the ability to remove each radionuclide without removing unacceptable amounts of the others in a given process step needs to be demonstrated. This type of study could be done on a coldlaboratory scale. 


\subsection{REFERENCES}

1. L. A. Hanson, Removal of Irradiated $\mathrm{UO}_{2}$ Fuel from Cladding by Controlled Oxidation, NAA-SR-3591, August 1959.

2. S. Strausberg and T. E. Luebben, Chemical Pulverization of Sintered Uranium Dioxide Bodies, Part I. Preliminary Small Scale Studies, NAA-SR3910, August 1959.

3. S. Strausberg, Chemical Pulverization of Sintered Uranium Dioxide Bodies, Part II. Pulverization Scale-up, Fissia Studies, and Pellet Refabrication, NAA-SR-3911, May 1960.

4. S. Strausberg, Multicycle Reprocessing and Refabrication Experiments on Simulated $\mathrm{UO}_{2}$-Fissia Pellets, NAA-SR-7138, August 1962.

5. J. Guon et. a1., Low Decontamination Reprocessing Studies on Irradiated Uranium Dioxide Reactor Fuel, NAA-SR-7136, November 1962.

6. J. Guon et. al., Refabrication and Encapsulation of Highly Irradiated Uranium Dioxide, NAA-SR-8213, December 1964.

7. J. E. Bodine et. al., "Oxidative Decladding of Uranium Dioxide Fuels," Nuclear Science and Engineering, 19, 1964.

8. J. E. Bodine et. al., Second-Cycle AIROX Reprocessing and Pellet Refabrication of Highly Irradiated Uranium Dioxide, NAA-SR-11375, August 1965.

9. J. G. Asquith and L. F. Grantham, "A Low-Decontamination Approach to a Proliferation-Resistant Fuel Cycle," Nuclear Technology, 41, December 1978, pp. 137-148.

10. L. F. Grantham et. al., "AIROX Dry Pyrochemical Processing of Oxide Fuels, A Proliferation-Resistant Reprocessing Method, "American Chemical Society Symposium Series 117, 1980, pp. 219-233.

11. Characteristics of Spent Fuel, High-Level Waste, and Other Radioactive Wastes Which May Require Long-Term Isolation, Office of Civilian Radioactive Waste Management, DOE/RW-0184, June 1988.

12. J. Guon, AIROX Reprocessing Facility, GEN-XR-007, September 1992.

13. J. Guon, Technical Gaps and R\&D Needs for AIROX Recycle of Spent LWR Fuel, GEN-XR-008, September 1992.

14. R. A. Brown et al., Airborne Radionuclide Waste Management Reference Document, ENIC0-1130, July 1983, pp. 2-101 to 2-150.

15. W. R. A. Goossens et al. (Eds.), Treatment of Gaseous Effluents at Nuclear Facilities, Chur, Switzerland: Harwood Academic Publishers, 1991. 


\section{REACTOR OPERATION AND SAFETY ISSUES}

This section presents the results of an investigation of the core physics and fuel behavior aspects of loading AIROX-processed fuel in an LWR. First, we evaluated the additional enrichment that will be required to counteract the poisoning effect of the fission products present in the fuel. We then examined the reactor control aspects of the AIROX-fueled core. We also evaluated the salient features of neutronics performance required for satisfactory operations. We concluded that with proper enrichment, suitable fuel management schemes, and control rod programming, the AIROX fuel can be used in an LWR. We did not have time to evaluate directly the regulatory implications of this fuel cycle, including source-term inventories.

\subsection{Reactivity Comparisons of Virgin and AiroX Fuel Assemblies}

Neutronics studies of AIROX-processed fuel have demonstrated that, for both ${ }^{235} \mathrm{U}$ and ${ }^{239} \mathrm{Pu}$ enhanced enrichment, the reactivity reduction due to the presence of fission products is small; and greater fuel utilization (both fissile and fertile) is achievable without limitations on reactor cycle length.

A simulation of AIROX-reprocessed fuel was performed for a typical $17 \times 17$ PWR fuel assembly of current design, with 24 guide tubes and one instrumentation thimble. The guide tubes and the instrumentation thimble were modeled as filled with flowing coolant (moderator). The fuel assembly modeled contained virgin $\mathrm{UO}_{2}$ enriched to $3.2 \mathrm{wt} . \%{ }^{235} \mathrm{U}$, with a heavy metal mass of 480 $\mathrm{kg} /$ assembly; it was irradiated to a maximum burnup of $33,000 \mathrm{MWd} / \mathrm{kgU}$.

After removal from the reactor, the fuel assembly resided for 5 years in the spent fuel pool before recycling. During AIROX recycling and resintering, the fuel assembly was assumed to have lost the following percentages of fission products: $100 \%$ of tritium, krypton, iodine, and carbon; $90 \%$ of cesium and ruthenium; and $75 \%$ of tellurium and cadmium. Also during recycling, enough ${ }^{235} \mathrm{U}$ or ${ }^{239} \mathrm{Pu}$ was added to produce recycled fuel equivalent in 
performance to a fuel assembly loaded with virgin fuel enriched to 4.3 wt.\%

${ }^{235} \mathrm{U}$. This represents a typical advanced reactor fuel assembly design intended for a total burnup of 55,000 MWd/MTU in three reactor operating cycles of two years each.

The recycled fuel designs chosen require either an additional $3.3 \mathrm{wt} . \%$ ${ }^{235} \mathrm{U}$ or an additional $4.0 \mathrm{wt} . \%{ }^{239} \mathrm{Pu}$. As shown in Figures $3-1$ through 3-4, either of these fuel designs yield satisfactory multiplication factors (kinfinity) and superior fissile and fertile fuel utilization over the virgin 4.3 wt.\% enriched assembly.

The fuel assembly reactor analysis was performed using the Studsvik code CASMO-3, ${ }^{1}$ with some input from ORIGEN2. ${ }^{2}$ The 3.2 wt.\% virgin fuel was depleted in CASMO-3 where the CASMO-3 k-library cross sections were used. This library is designed for high burnup and high actinide content, where the epithermal resonances in the actinides are treated satisfactorily. The CASMO3 code evaluates the cross sections at each burnup step; thus, it has exposure- and burnup-dependent cross sections at all fuel histories. The code also prints out 40 of the fission product concentrations explicitly and has two fission product categories, saturating and non-saturating.

A few of the volatile isotopes removed during recycling and resintering were not represented explicitly in CASMO-3. These corresponded to less than $10 \%$ of the absorption rate of all volatiles removed, as evaluated in ORIGEN2. A set of separate ORIGEN2 runs at constant flux were made to simulate the absorption rates and concentrations of these isotopes in the recycled fuel during irradiation to high burnups. Thus, it was possible to conservatively simulate the removal of these few isotopes, using ${ }^{152} \mathrm{Sm}$ and ${ }^{155} \mathrm{Eu}$. It is important to note that both of these isotopes are at the end of their chains; thus, their removal accounted for absorption rates associated with daughter isotopes as we11. Figure 3-5 shows the infinitely repeated assembly multiplication factor as a function of burnup for both virgin and reprocessed fuel at 4.3 and $3.3 \mathrm{wt} . \%$ enrichment, respectively. As shown, the total worth of the volatiles, even if they were not removed, is less than $5 \%$. 


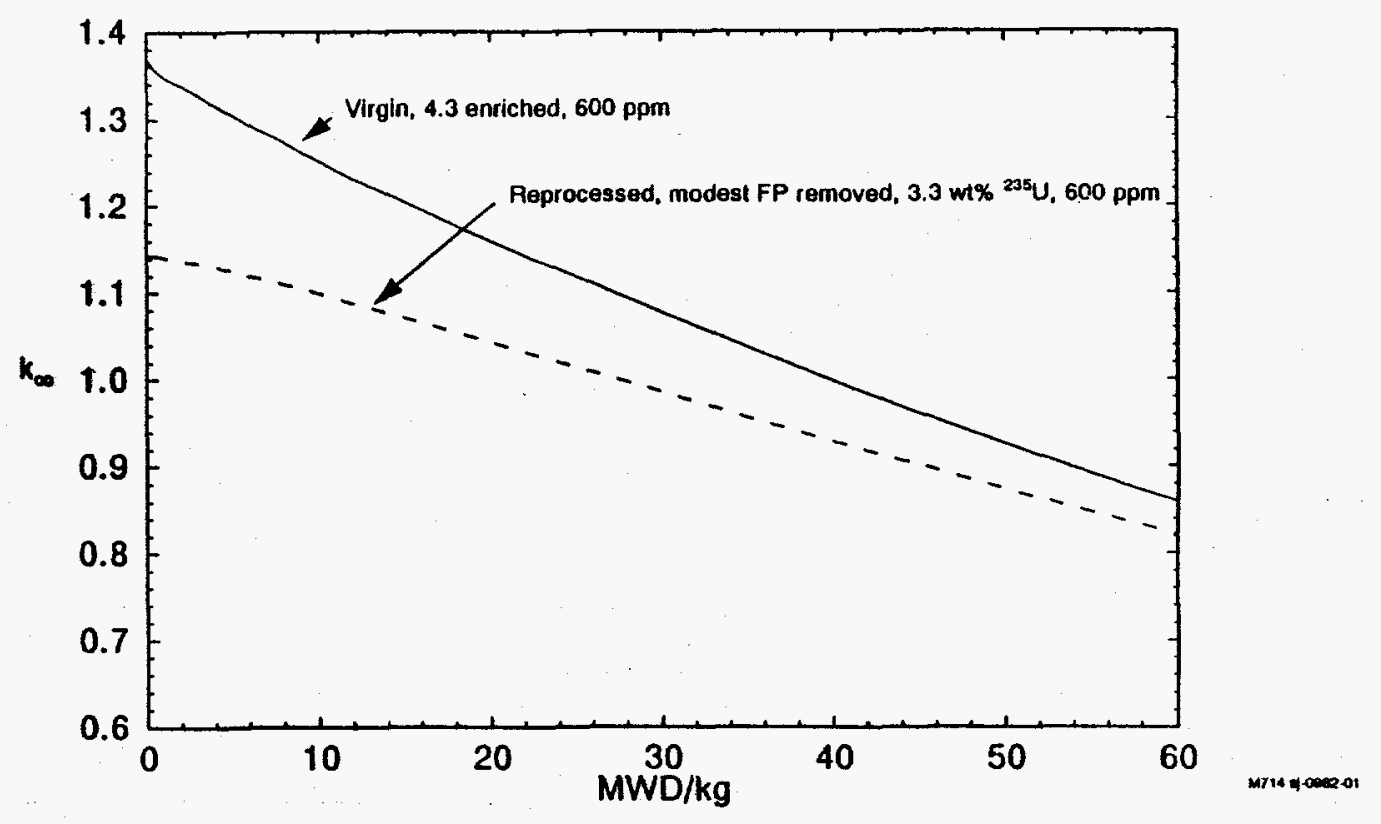

Figure 3-1. Comparison of the infinite multiplication factor, $k-\infty$ for virgin $4.3 \mathrm{wt} . \%{ }^{235} \mathrm{U}$-enriched fuel and AIROX-recycled fuel with $3.3 \mathrm{wt} . \%{ }^{235} \mathrm{U}$ (reprocessed from $3.2 \mathrm{wt} . \%$ virgin fuel with $33 \mathrm{MWd} / \mathrm{kg}$ burnup).

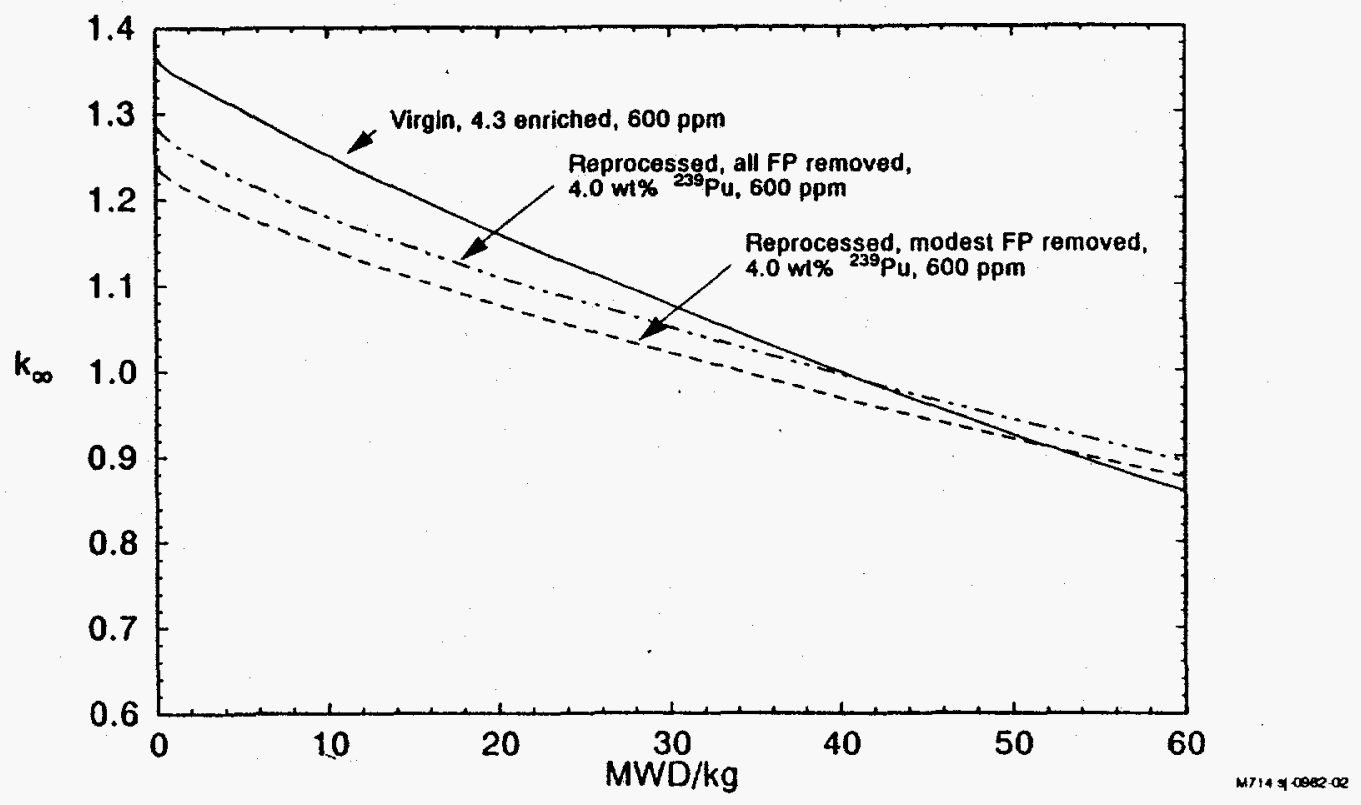

Figure 3-2. Comparison of the infinite multiplication factor, $k-\infty$ for virgin $4.3 \mathrm{wt} . \%{ }^{235} \mathrm{U}$-enriched fuel and AIROX-recycled fuel with $4.0 \mathrm{wt} . \%{ }^{239} \mathrm{Pu}$ (reprocessed from $3.2 \mathrm{wt} . \%$ virgin fuel with $33 \mathrm{MWd} / \mathrm{kg}$ burnup). 


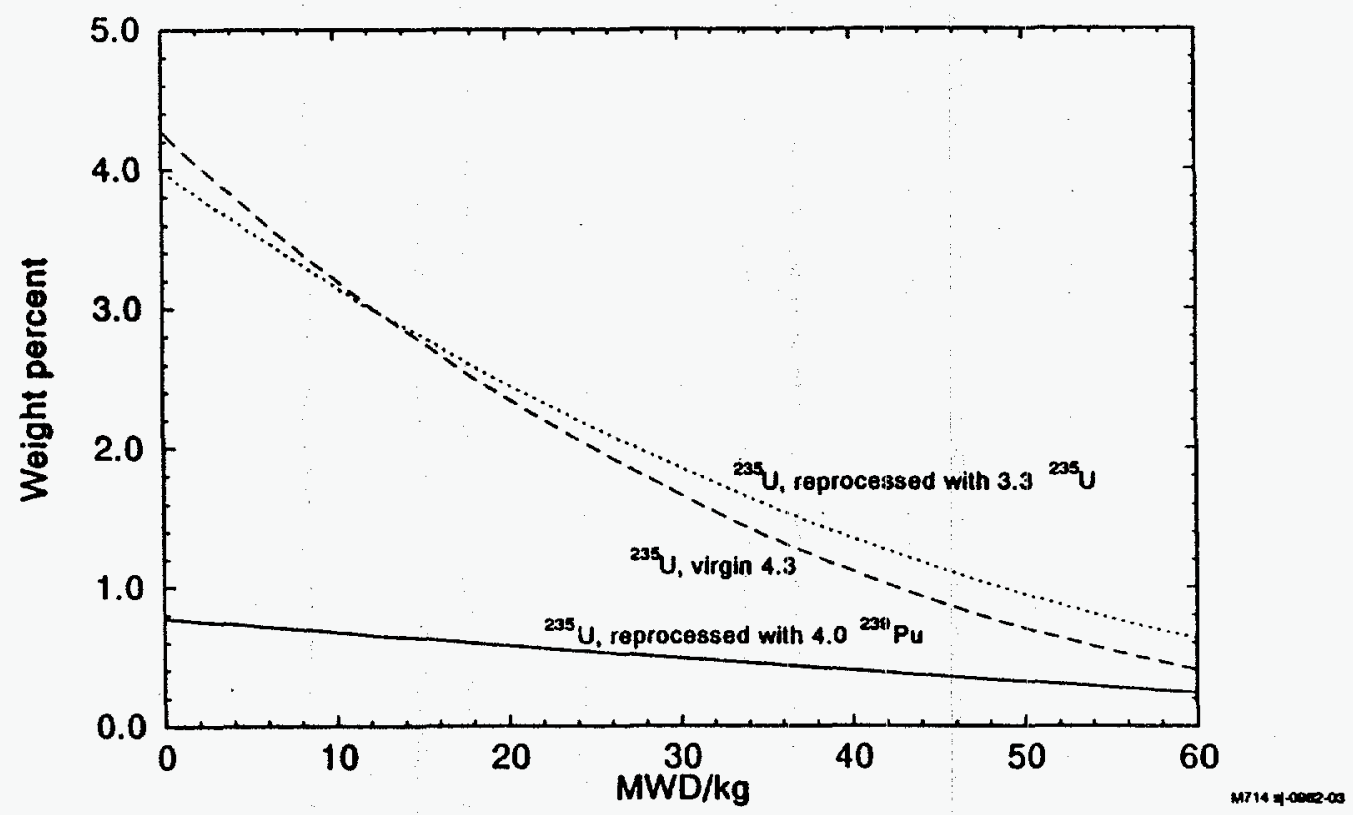

Figure 3-3. Comparison of the fissile ${ }^{235} \mathrm{U}$ utilization for the virgin fuel and the two reprocessed fuels of Figures 3-1 and 3-2.

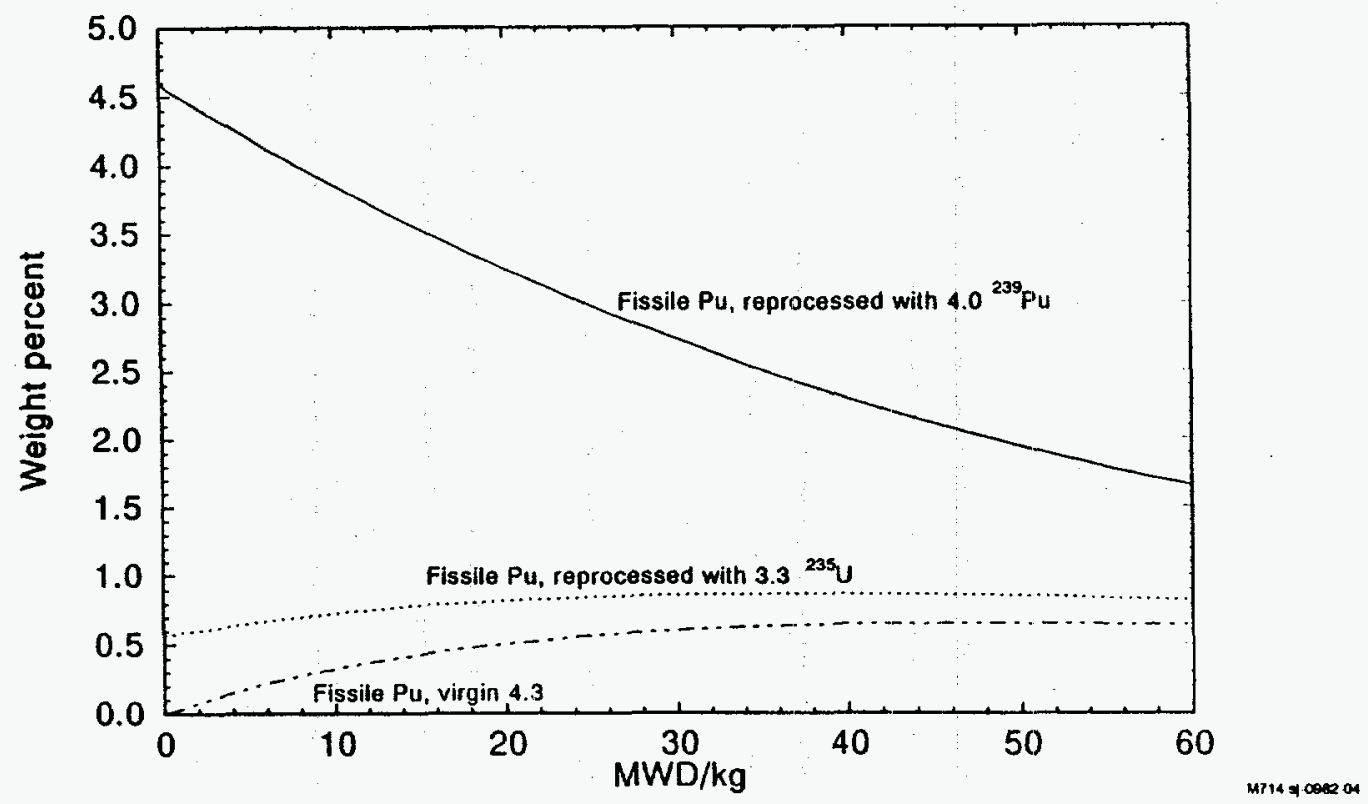

Figure 3-4. Comparison of the fissile $\mathrm{Pu}$ (total ${ }^{239} \mathrm{Pu}$ and ${ }^{241} \mathrm{Pu}$ ) for the virgin fuel and the two reprocessed fuels of Figures 3-1. and 3-2. 


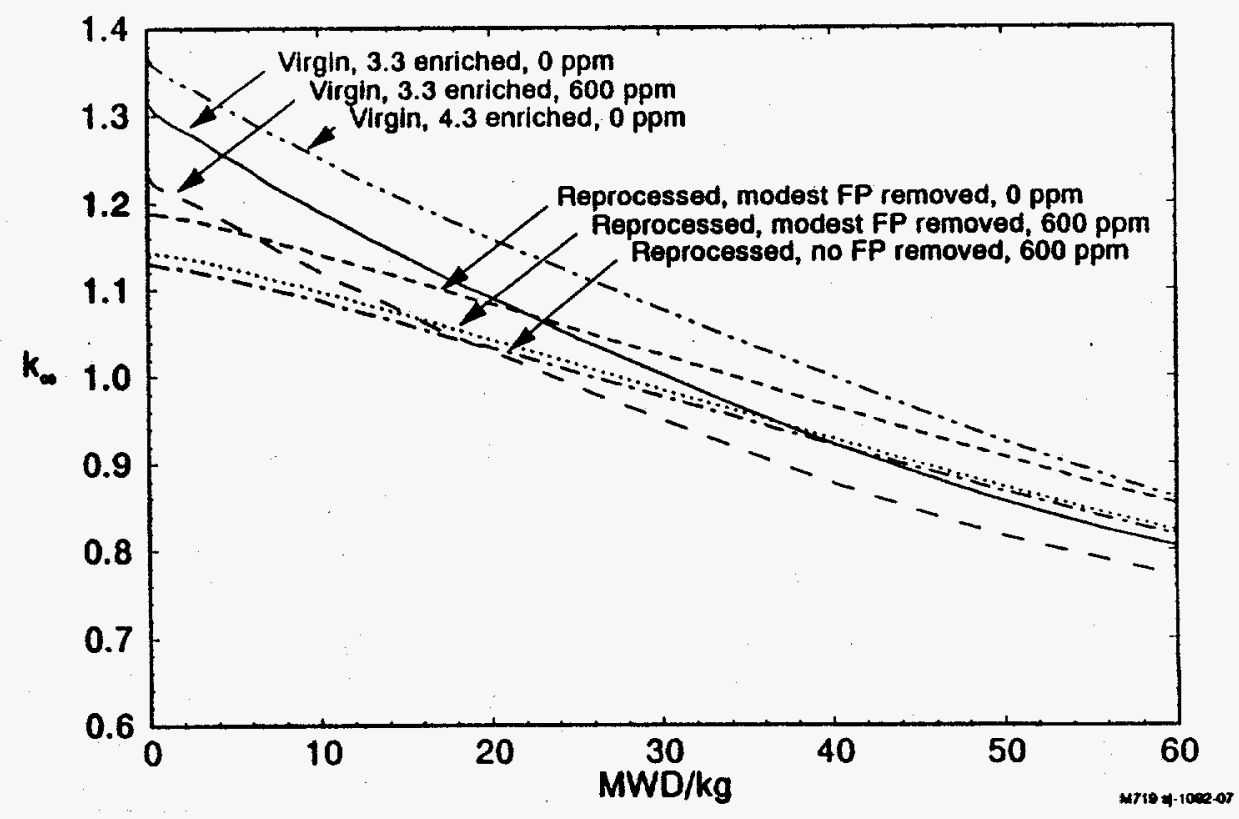

Figure 3-5. The infinitely repeated assembly multiplication factor as a function of burnup for the recycled fuel and for the virgin fuel at 3.3 and $4.3 \mathrm{wt} . \%$ enrichment. Included are several cases showing the boron and fission product worths throughout the fuel life.

The impact of fission product retention on reactivity (k-infinity) is not a major factor (see Figure 3-5). In fact, the two largest absorbers, xenon and samarium, are essentially dependent on the power level and not on the initial concentrations in the fuel, for most of the operating life. Further, the presence of the fission product absorbers near the beginning of cycle means that burnable absorbers will not be needed in the recycled fuel, as is the case with virgin fuel reloads.

The above demonstrates that AIROX-recycled fuel yields advantages in fuel recycling as well as greater utilization of the fissile and fertile isotopes at no compromise in cycle length. 


\subsection{Power Peaking and other Reactor Core Issues}

In the recycled fuel, there are two features that affect reactor neutronics--the presence of fission products and the larger amounts and variety of actinides. This section addresses how the reactivity worth of control elements (control rods, shutdown rods, and soluble boron) is affected by the presence of other absorbers.

As is demonstrated in Figures 3-6 through 3-8. the neutron spectrum in the reprocessed fuel is harder than that in the virgin fuel. Further, the spectral hardening is more pronounced for fuel reprocessed with fissile plutonium than for that reprocessed with fissile uranium. The fission products and the actinides in the reprocessed fuel al so contribute to lower reactivity worth for any poison used in control or shutdown. This is readily observed in Figure 3-5. The moderator temperature coefficient of reactivity and the Doppler coefficient in the resonance absorbers will also be similarly affected by the presence of fission products and actinides in the reprocessed fuel, as will be shown below. The temperature expansion defect in the fuel is also expected to change, based on the change in physical characteristics in the reprocessed fuel compared to the virgin fuel.

In Figures 3-6 to 3-8, the absolute thermal, fast, and total flux intensities are given as evaluated in CASMO-3 for the various fuels considered. Note that the thermal flux in the recycled fuel can be as low as $50 \%$ that of the virgin $3.3 \mathrm{wt} . \%$ fuel. The fast flux is markedly lower, and the total flux is as much as $30 \%$ lower. This predicts considerable power peaking in fuel pins of virgin fuel adjacent to recycled fuel pins and will require more sophisticated fuel reload analysis than is exercised in allvirgin-fuel design.

As shown in Table 3-1, the worth of $B_{4} C$ control rods in reprocessed fuel can be up to $30 \%$ below that in virgin fuel throughout the fuel life cycle. Similarly, the boron worth in the moderator will be up to $30 \%$ below that in the virgin fuel. Both of these impacts can be counteracted by fuel management schemes, and most effectively by the use of enriched boron. 


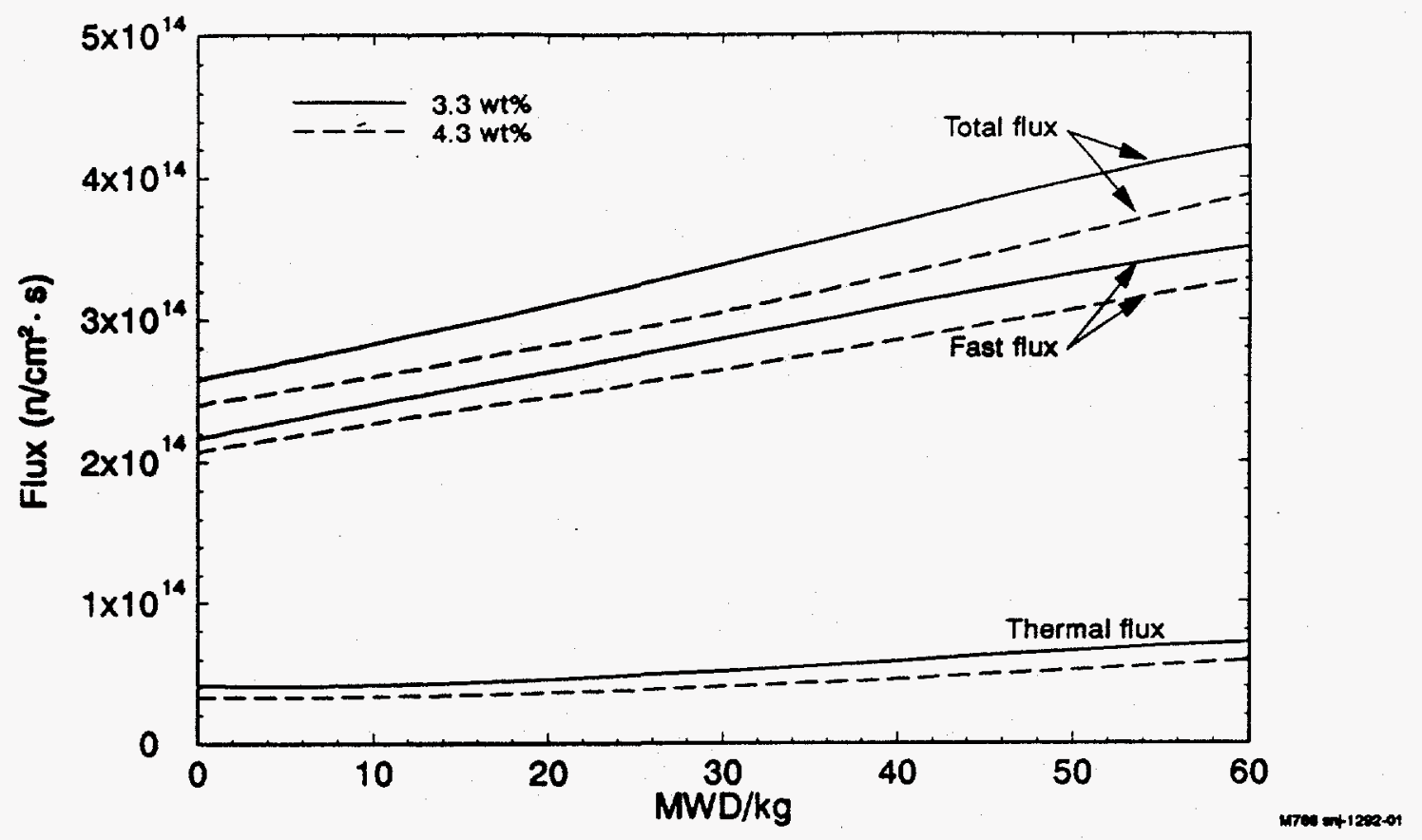

Figure 3-6. Thermal and fast flux densities throughout the fuel life for virgin 3.3 and $4.3 \mathrm{wt} . \%{ }^{235} \mathrm{U}$-enriched fuel burned at $600 \mathrm{ppm}$ boron and 36 $\mathrm{W} / \mathrm{gU}$.

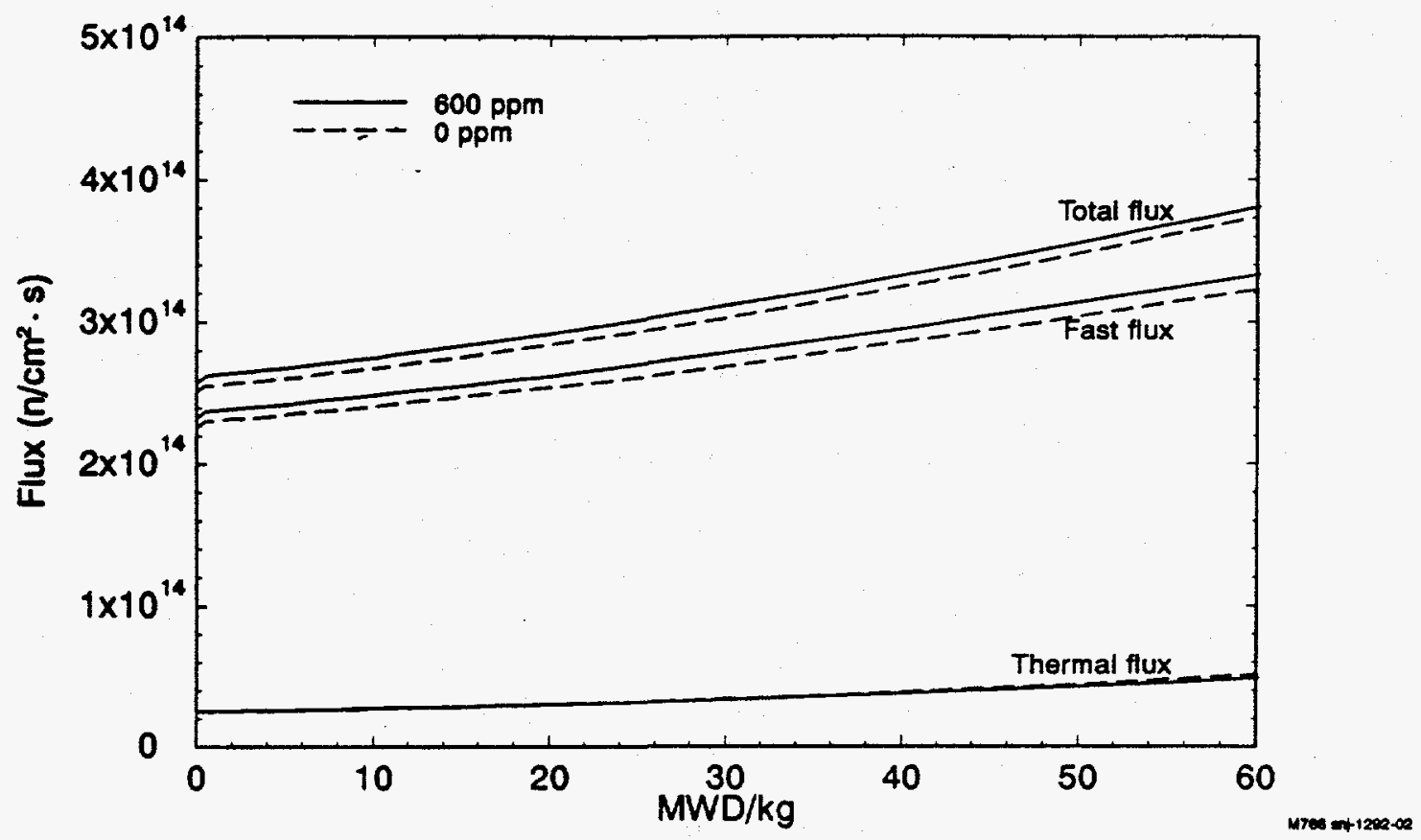

Figure 3-7. Thermal and fast flux densities throughout the fuel 1 ife for AIROX-reprocessed $3.3 \mathrm{wt} . \%{ }^{235} \mathrm{U}$-enriched fue 7 burned at 0 and $600 \mathrm{ppm}$ boron and $36 \mathrm{~W} / \mathrm{gU}$. 


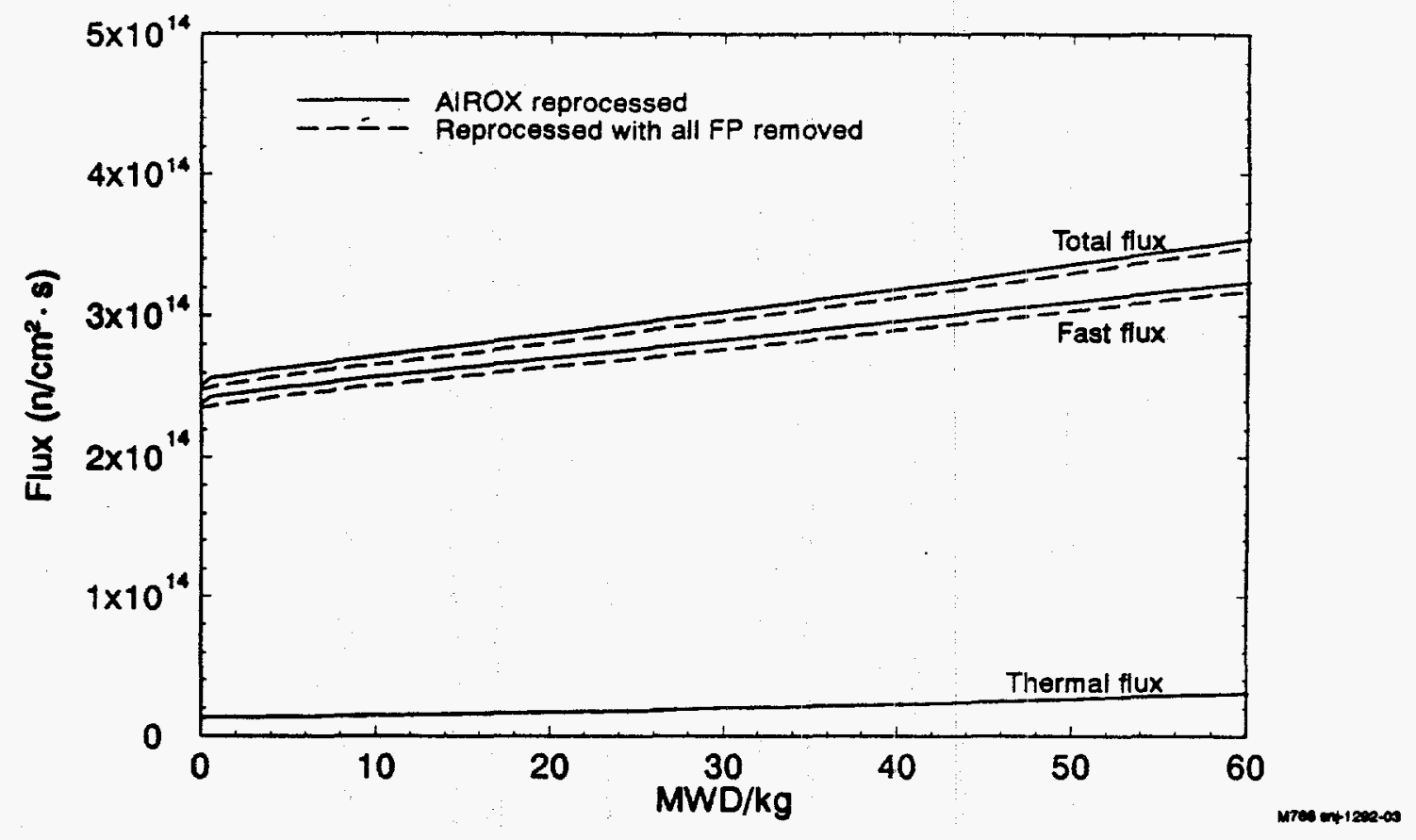

Figure 3-8. Thermal and fast flux densities throughout the fuel iife for AIROX-reprocessed $4.0 \mathrm{wt} . \%{ }^{239} \mathrm{Pu}$-enriched fuel burned at $600 \mathrm{ppm}$ boron and 36 $W / g U$.

The hard spectrum demonstrated above (Figures 3-6 through 3-8) also means that there will be differences in reactivity worths with respect to control element insertion, Doppler defects, and moderator temperature defects between virgin and reprocessed fuel. The moderator temperature coefficient (MTC) at a few comparable states is 1 isted in Table 3-2. For example, the large negative MTC at end of life in the reprocessed fuel means it will have a relatively larger effect on the steam line break accident scenario.

In Table 3-3, the reactivity conditions at the end of a fairly long operating cycle ( 2 years, or $19 \mathrm{Mwd} / \mathrm{kgU}$ ) are compared between an all-virginfuel loading and a similar core loaded with $1 / 3$ reprocessed fuel, spiked with either ${ }^{235} \mathrm{U}$ or ${ }^{239} \mathrm{Pu}$. The control, shutdown, and soluble boron worths in the core loaded with recycled fuel will be under $10 \%$ less than for the core fully loaded with virgin fuel. The moderator temperature coefficient is about $30 \%$ more negative in the core loaded with $1 / 3$ reprocessed fuel. Finally, the overall total defect is also more negative for the recycled fuel. These 
Table 3-1. Comparison of rod worth [100 (ln $\left.\left.k_{2} / k_{1}\right)\right]\left(B_{4} C\right.$ rod clusters) in standard Westinghouse $17 x 17$ pin fuel assemblies at full power with full xenon concentrations at beginning, middle, and end of 1 ife.

\begin{tabular}{|c|c|c|c|c|}
\hline Fuel cycle status & $\begin{array}{l}\text { Virgin fuel, } \\
4.3 \text { wt. } \%{ }^{235} \mathrm{U}\end{array}$ & $\begin{array}{l}3.2 \text { wt.\% }{ }^{235} U \text {, } \\
33 \mathrm{GWd} / \mathrm{MTU} \text { burnup, } \\
\text { reprocessed with } \\
3.3 \text { wt.\% }{ }^{235} \mathrm{U}\end{array}$ & $\begin{array}{l}3.2 \text { wt. } \%{ }^{235} \mathrm{U}, \\
33 \text { GWd/MTU burnup, } \\
\text { reprocessed with } \\
4.0 \text { wt. } \%{ }^{239} \mathrm{Pu}\end{array}$ & $\begin{array}{l}3.2 \text { wt.\% }{ }^{235} \mathrm{U}, \\
33 \text { GWd/MTU burnup, } \\
\text { reprocessed with } \\
4.0 \text { wt. } \%{ }^{239} \mathrm{Pu}, \\
\text { fission products } \\
\text { removed }\end{array}$ \\
\hline Beginning of life & -38.49 & -33.02 & -27.35 & -27.76 \\
\hline Middle of $1 \mathrm{ife}$ & -38.03 & -34.64 & -29.12 & -29.58 \\
\hline End of life & -39.60 & -36.57 & -31.50 & -32.11 \\
\hline
\end{tabular}

Table 3-2. Comparison of moderator temperature coefficient (pcm/K) at zero power, $600 \mathrm{ppm}$ boron, at beginning, middle, and end of life.

\begin{tabular}{|c|c|c|c|c|}
\hline Fuel cycle status & $\begin{array}{l}\text { Virgin fuel, } \\
4.3 \text { wt.\% }{ }^{235} \mathrm{U}\end{array}$ & $\begin{array}{l}3.2 \text { wt. } \%{ }^{235} \mathrm{U}, \\
33 \mathrm{GWd} / \mathrm{MTU} \text { burnup, } \\
\text { reprocessed with } \\
3.3 \text { wt. } \%{ }^{235} \mathrm{U}\end{array}$ & $\begin{array}{l}3.2 \text { wt. } \%{ }^{235} \mathrm{U} \\
33 \text { GWd/MTU burnup, } \\
\text { reprocessed with } \\
4.0 \text { wt. } \%{ }^{239} \mathrm{Pu}\end{array}$ & $\begin{array}{l}3.2 \text { wt.\% }{ }^{235} \mathrm{U}, \\
33 \mathrm{GWd} / \mathrm{MTU} \text { burnup, } \\
\text { reprocessed with } \\
4.0 \text { wt.\% }{ }^{239} \mathrm{Pu}, \\
\text { fission products } \\
\text { removed }\end{array}$ \\
\hline $\begin{array}{l}\text { Beginning of life, } \\
\text { without xenon }\end{array}$ & -12.64 & -40.09 & -50.03 & -42.04 \\
\hline $\begin{array}{l}\text { Beginning of life, } \\
\text { with xenon }\end{array}$ & -12.67 & -36.56 & -46.03 & -45.81 \\
\hline $\begin{array}{l}\text { Middle of life, } \\
\text { without xenon }\end{array}$ & -28.66 & -43.44 & -56.55 & -53.84 \\
\hline $\begin{array}{l}\text { End of } 1 \text { ife, } \\
\text { without xenon }\end{array}$ & -21.98 & -37.91 & -53.49 & -51.56 \\
\hline
\end{tabular}


Table 3-3. Comparison of end-of-reactor-cycle (19 MWd/kgU) reactivity data for the equilibrium cycle loading with $100 \%$ virgin fuel (initial enrichment. $4.3 \mathrm{wt} \%{ }^{235} \mathrm{U}$ ) to the end-of-reactor-cycle reactivity data of equilibrium cycles loaded with reprocessed fuel in one-third of the core.

\begin{tabular}{|c|c|c|c|}
\hline Core loading & $100 \%$ virgin fuel & $\begin{array}{c}33.3 \% \text { fuel } \\
\text { reprocessed with } \\
3.3 \text { wt\% }{ }^{235} \mathrm{U}, \\
66.67 \% \text { virgin } \\
\text { fuel }\end{array}$ & $\begin{array}{c}33.3 \% \text { fuel } \\
\text { reprocessed with } \\
4.0 \text { wt\% }{ }^{239} \mathrm{Pu}, \\
66.67 \% \text { virgin } \\
\text { fuel }\end{array}$ \\
\hline $\begin{array}{l}\text { Relative control } \\
\text { and shutdown } \\
\text { worths }(\%)\end{array}$ & 100.00 & 97.00 & 92.19 \\
\hline $\begin{array}{l}\text { Moderator } \\
\text { temperature } \\
\text { coefficient } \\
\text { without xenon } \\
(\mathrm{pcm} / \mathrm{K})\end{array}$ & -28.67 & -33.45 & -37.78 \\
\hline $\begin{array}{l}\text { Total defect from } \\
\text { cold zero power } \\
\text { to hot full } \\
\text { power, with xenon } \\
\left(\% \Delta \mathrm{k} / \mathrm{k}_{\text {avo }}\right)\end{array}$ & -1.6 & -2.11 & -2.61 \\
\hline
\end{tabular}

reductions, on a core-wide basis, relative to the assembly-wise comparisons in the previous section, indicate that there is a large degree of design flexibility available to modify the various reactivity differences.

In the single-fuel-assembly analyses, it was assumed that the added enrichment material came from $100 \%$ fissile material. In reality, this material may have over $80 \%$ fertile $\left({ }^{238} \mathrm{U}\right)$ fuel or may have uranium enrichment tailings added deliberately to it. In such cases, many of the reactor design characteristics studied earlier will change. This is due to the reduction in the relative content of fission products and actinides in the recycled fuel. Thus, the differences between virgin and AIROX-recycled fuel performance would decrease further. However, reprocessing with spiked fuel that is heavily loaded with fertile fuel would decrease the reduction of high-level waste in AIROX recycling. An optimization evaluation, taking into consideration these two opposing goals, will have to be made for an optimal AIROX reprocessing fuel cycle strategy. 
The control, shutdown, and soluble boron worth in the cores loaded with recycled fuel will be under $10 \%$ less than in the core fully loaded with virgin fuel. The moderator temperature coefficient is about 30\% more negative in the cores loaded with one-third recycled fuel. Finally, the overall total defect is also more negative for the recycled fuel. These reductions, on a core-wide basis relative to the assembiy-wise comparisons in the previous section, indicate that there is a large degree of design flexibility available to modify the various reactivity differences.

The fuel expansion coefficient and thermal conductivity are not known for the reprocessed fuel and are assumed for the present to be equal to that for the virgin fuel. The Atomics International experimental data indicated a rise in theoretical density, as mentioned in Section 2.

The impact on the reactor vessel due to a harder neutron spectrum and greater leakage of fast neutrons streaming into the vessel has not been evaluated. However, comparison of the fast flux level for a core loaded with one-third plutonium-recycled fuel to a reactor core loaded with all virgin fuel leads to only an $-5 \%$ increase. This increase in vessel fluence can be overcome with standard core loading techniques. 


\subsection{FUel Behavior Studies}

A preliminary investigation was conducted to identify those fuel behavior mechanisms requiring additional evaluation for AIROX-processed fuel. First, the current LWR fuel behavior data base, existing LWR fuel behavior models, and currently ongoing extended burnup and severe accident programs were examined and evaluated as to their applicability to AIROX-processed fuel. Based on these findings, several important fuel behavior mechanisms that may require specific evaluation for AIROX-processed fuel were identified.

\subsubsection{LWR Fuel Behavior Data Base}

The following section summarizes the existing LWR fuel behavior data base and discusses its applicability to AIROX-processed fuel.

3.3.1.1 A Description of the Existing LWR Fuel Behavior Data Base. The existing LWR fuel behavior data base includes both in-reactor and ex-reactor data for normal operating conditions, design basis accidents (DBAs), and severe accidents (SAs).

The existing LWR fuel behavior data base for normal operating conditions is very extensive, due to the great number of operating LWRs worldwide, but is limited for high-burnup conditions. The data base is being extended for highburnup conditions, however, through Department of Energy (DOE) and U. S. Nuclear Regulatory Commission (NRC) extended-burnup programs and vendor/utility in-reactor programs.

The existing in-reactor LWR fuel behavior data base for DBAs consists primarily of the results from programs conducted in two facilities--the Power Burst Facility (PBF), located at the INEL, and the Halden Boiling Water Reactor (HBWR), located in Halden, Norway. The PBF reactor was designed to expose single fuel rods and small clusters of fuel rods to a range of power and energy densities and was operated in three modes: (a) a steady-state mode, with power levels up to $28 \mathrm{MW}$; (b) a natural power burst mode, with reactor periods as short as $1.0 \mathrm{~ms}$ and peak powers as 1 arge as $270 \mathrm{GW}$; and (c) 
a shaped burst mode, with energy generations up to $1350 \mathrm{MJ}$ (1350 MW-s). PBF was thus suited to provide the power and energy in test fuel rod clusters for a broad spectrum of postulated reactor accidents. The HBWR provided a longterm irradiation environment to provide data on irradiation effects on steadystate fuel rod behavior and on gas adsorption and release and axial gas flow within fuel rods.

The Thermal Fuels Behavior Program conducted in PBF consisted of test series that addressed (a) the behavior of PWR-type fuel rods during powercooling mismatch conditions (PCM); (b) the behavior of irradiated fuel rods under PCM conditions (IR); (c) the effects of fuel design parameters on the magnitude of fuel-cladding gap conductance (GC); (d) the threshold energy limits of incipient fuel rod failure and prompt fuel dispersal for test environments typical of power reactor conditions.

The existing in-reactor LWR fuel behavior data base for severe accidents (SA) includes data from the PBF loss-of-coolant accident (LOCA) and severe fuel damage (SFD) tests; the Loss-of-Fluid Test Facility (LOFT) test series; and the Annular Core Research Reactor (ACRR) and National Reactor Universal (NRU) test series.

\subsubsection{Applicability of the Existing LWR Fuel Behavior Data Base to} AIROX-Processed Fuels. Much of the existing LWR fuel behavior data base should be applicable to AIROX-processed fuels. Basic materials properties are expected to fall within the existing data base for $\mathrm{UO}_{2}$ and $\mathrm{PuO}_{2}$ fuels; however, the unique fission product chemistry of AIROX fuel may need to be evaluated. Since the reprocessed fuel microstructure is an important parameter in fuel behavior, the initial fuel characterization should identify potential long-term behavior.

\subsubsection{LWR Fuel Behavior Models}

The following section summarizes the existing LWR fuel behavior models and discusses their applicability to AIROX-processed fuel. 
3.3.2.1 A Description of Existing LWR Fuel Behavior Models. The existing fuel behavior codes include FRAPCON-2, FRAP-T6, and SCDAP/RELAP5/MOD3.

The FRAPCON-2 code was developed to calculate the steady-state response of LWR fuel rods during long-term burnup. It calculates the temperature, pressure, deformation, fission product release, and failure histories of a fuel rod as functions of time-dependent fuel rod power and coolant boundary conditions.

The FRAP-T6 code was developed to predict the performance of LWR fuel rods during operational transients and hypothetical accidents. The code can calculate initial fuel rod conditions or obtains them by reading a file created by the FRAPCON-2 code. The FRAP-T6 code calculates all of the phenomena influencing the transient performance of fuel rods, with particular emphasis on temperature, cladding deformation, and fission product release.

The SCDAP/RELAP5/MOD3 code is a LWR transient analysis code designed to provide the overall reactor coolant system thermal-hydraulic response, core damage progression, and fission product release and transport during severe accidents. SCDAP/RELAP5/MOD3 is a combination of RELAP5/M0D3, SCDAP, and TRAP-MELT models. The RELAP5/MOD3 models calculate the overall reactor coolant system thermal-hydraulics, control system interactions, reactor kinetics, and the transport of noncondensable gases, fission products, and aerosols. The SCDAP models calculate the damage progression in the core structures and the formation, heat up, and melting of debris. The TRAP-MELT models calculate the deposition of fission products upon aerosols or structural surfaces; the formation, growth, or deposition of aerosols; and the evaporization of species from surfaces. These models are fully coupled at each time step.

\subsubsection{Applicability of Existing LWR Fuel Behavior Models to AIROX-} Processed Fuels. The existing LWR fuel behavior models should be generally applicable to AIROX-processed fuel from normal operating to severe accident conditions. However, new correlations may be required for pellet-cladding interactions, fission product release, and extended burnup. 


\subsubsection{Ongoing LWR Programs Incorporating Fuel Behavior Studies}

The following section summarizes ongoing LWR programs that include fuel behavior studies and discusses their applicability to AIROX-processed fuel.

\subsubsection{A Description of Ongoing LWR Programs Involving Fuel Behavior} Studies. The NRC is currently sponsoring research on several advanced reactor designs. Fuel for one of these reactor concepts will be designed for a region-average burnup of $60,000 \mathrm{MWd} / \mathrm{MTU}$. As part of this program, SCDAP/RELAP5/MOD3 fuel behavior models are being modified to perform severe accident analysis at high-burnup levels. There are several areas of modeling in which current fuel models cannot representing phenomena occurring at high burnup: (a) loss of grain structure and formation of voids, or the rim effect; (b) the variation in fission product release due to these changes in grain structure; (c) a large radial peaking factor due to plutonium buildup; and (c) material properties.

\subsubsection{Applicability of Ongoing LWR Fuel Behavior Programs to AIROX-} Processed Fuels. Existing programs to investigate extended burnup will help resolve questions regarding the use of AIROX-processed fuel at burnups greater than 60,000 MWd/MTU.

\subsubsection{Fuel Behavior Mechanisms Requiring Specific Evaluation for AIROX- Processed Fuel}

Based on this evaluation, several important fuel behavior mechanisms that may require specific evaluation for AIROX-processed fuel were identified. These include:

- Fuel morphology and the associated restructuring with increased burnup should be investigated. These investigations should include fission product release and chemistry; decay heat generation; fuel/cladding gap conductance; and potential failures due to pellet-cladding interactions. 
- Fuel behavior associated with severe accidents should be investigated. These investigations should include fuel rod deformation and rupture (local temperature gradients), liquefaction of the fuel and cladding, and late-phase melt behavior (fission product release and chemistry).

\subsubsection{Implications for the Licensing of AIROX Fuel}

The AIROX fuel should not represent any unique challenges to licensing for use in commercial power plants from a fuel-performance perspective. For normal and design basis accident conditions, the results from existing fuel behavior programs, in combination with in-reactor lead rod programs comparable to those used for the introduction of new fuel designs, should be sufficient to qualify AIROX processed fuel. For severe accident conditions, because of the potential impact of the somewhat unique fuel chemistry upon reactor source terms, analysis beyond that required for typical new fuel designs may be required to ensure that source term margins remain within licensing limits.

However, the licensing implications associated with (a) the changes in core neutronics, and associated potential changes in core design, and (b) the potential for different fuel handling and quality assurance requirements will have to be evaluated. The changes in core neutronics should be handled principally through design basis accident analysis associated with transients such as Reactivity Initiated Events or Anticipated Transient Without Scram Events to ensure that the changes in the core design associated with the AIROX process do not result in unacceptable variations in reactor performance under accident conditions. Such analysis should be comparable to that performed with the introduction of other new fuel designs. The impact of the changes in remote fuel handling and quality assurance requirements is more difficult to evaluate and may be the most serious constraint to the licensing process.

\subsection{References}

3-1. M. Edenius and B. Forssen, CASMO-3, Version 4.4, A Fuel Assembly Burnup Program, Studsvik/NFA-89/3.

3-2. A. G. Croft, ORIGEN2--A Revised and Updated Version of the Oak Ridge I sotope and Depletion Code, ORNL-5621, 1980. 


\section{WASTE MANAGEMENT ASPECTS OF AIROX PROCESSING}

As mentioned in the Introduction, one of our objectives is to examine whether the AIROX recycling process could help in the reduction of total high level waste for the commercial nuclear power industry. New wastes generated as a result of the recycling process will include the separated cladding and hardware, volatile fission products, and LLW. Also, the D\&D waste from the new facilities will have to be considered. Our analysis indicates that the total volume of high-level waste requiring disposal in a repository will be decreased by this recycling process; however, additional LLW will be generated.

In performing the waste generation analysis, several assumptions have been made. Some of these assumptions are debatable. For example, the time required to fully develop and build AIROX recycling facilities is unknown, and we may have assumed too high a number for the capacity of the facilities. Thus, the results reported here should be taken more as an indicator of trends rather than exact numbers.

\subsection{Disposition of Wastes Generated Via the AiroX Process}

Based on the analysis given in Section 2.2.1, the waste generated per MTIHM spent fuel processed would be:

- $\quad 0.29 \mathrm{MT}\left(0.045 \mathrm{~m}^{3}\right)$ of cladding and hardware as GTCC waste in ingot form,

- 0.103 MT $\left(0.038 \mathrm{~m}^{3}\right.$ or 0.061 canister) of GTCC waste containing semivolatiles in a glass waste form,

- 0.66 cylinder of krypton and xenon, 
- $\quad 0.19 \mathrm{~m}^{3}$ or 0.905 drum (55-gal capacity) of LLW containing HTO and

${ }^{14} \mathrm{C}$ as a barium carbonate in concrete,

- $\quad 1.89 \mathrm{~m}^{3}$ or 9 drums of LLW containing secondary LLW (rags, sludge, ash, etc.) in concrete, and

- $1.21 \mathrm{~L}$ of silver-impregnated zeolite containing $221 \mathrm{~g}$ of iodine.

The amount of wastes that would be generated in one year from a $500 \mathrm{MT} / \mathrm{y}$ plant would be 145 MT $\left(22.5 \mathrm{~m}^{3}\right)$ of cladding and hardware, 30.5 canisters of glass, 330 cylinders of krypton and xenon, 5000 drums of LLW, and $0.6 \mathrm{~m}^{3}$ (about three-55 gal drums) of iodine waste.

As indicated above, for every MT of spent fuel processed, 0.29 MT of GTCC cladding and hardware waste would be produced. The current U.S. policy regarding GTCC wastes dictates that any radioactive waste that doesn't qualify as LLW must be disposed of in a federal repository. The DOE Office of LWR Safety \& Technology and PNL ${ }^{4-1,2}$ have studied reducing constituent amounts of $\mathrm{N}, \mathrm{Ni}, \mathrm{Co}, \mathrm{Nb}$, and Mo in fuel assembly $\mathrm{cladding}$ and hardware to levels in which their activation products (i.e., ${ }^{14} \mathrm{C},{ }^{59} \mathrm{Ni},{ }^{63} \mathrm{Ni},{ }^{80} \mathrm{Co},{ }^{94} \mathrm{Nb}$, and ${ }^{99} \mathrm{TC}$ ) would qualify as LLW." The possibility of reducing these constituents to such low levels that cladding and hardware could be recovered and recycled in new assemblies was also considered. It was concluded that (a) $\mathrm{Ni}$ probably could not be eliminated from stainless steel and Inconel components because it was a principal alloying ingredient and (b) Nb could not be eliminated from zircaloy cladding because it was a principal corrosion-resistant ingredient needed for long in-core residence times use in modern LWR plant and fuel designs. It is therefore appropriate that the cladding be treated as GTCC waste.

In this study, the possibility of recycling cladding and hardware for use in the reconstituted fuel assemblies via AIROX was not examined. The preconceptual AIROX facility design assumes that new assemblies would be made

a. P. M. Lang, U.S. Department of Energy, private communication. 
from non-radioactive metals and that spent assembly hardware and cladding would be treated as GTCC waste.

The GTCC glass wastes ( 0.103 MT/MTIHM processed) volume is dictated by the heat load from ${ }^{134} \mathrm{Cs}$ and ${ }^{137} \mathrm{Cs}$, which restricts the radioactive waste loading to less than $5 \%$ by weight of the glass. Based on repository specification heat loads and canister placement geometry, an upper limit of 5200 watts per canister has been calculated.' Higher waste loadings (about $17 \%$ ) and less glass waste/MTIHM (about 0.03 MT or 0.018 canister) would result if the ${ }^{134} \mathrm{Cs}$ were allowed to decay 10 years. However, trade-off studies on storage and decay versus assumed direct disposal of GTCC semi-volatile wastes in a repository have not been conducted.

Although conceptual designs for above-ground and near-surface geological disposal of ${ }^{85} \mathrm{Kr}$ have been developed, ${ }^{4-3}$ no regulatory guidelines exist for the ultimate disposition of pressurized cylinders of ${ }^{85} \mathrm{Kr}$. It was assumed in this study that the cylinders would be stored on-site at the AIROX processing facility and the costs of ultimate disposal were not considered.

Current regulatory guidelines and burial grounds exist for handling $L L W$, and disposal of $L L W$ is a routine practice. The disposal of the 10 drums of LLW/MTIHM would cost about $\$ 7400$, based on an estimated charge rate of $\$ 100 / \mathrm{ft}^{3}$.

Under current regulatory guidelines, ${ }^{129} \mathrm{I}$ could be disposed of as LLW or as GTCC waste. In this study, it was assumed that the ${ }^{129} \mathrm{I}$ would be stored for potential future transmutation. This assumption was made due to an increased recognition that ${ }^{129} \mathrm{I}$ would be one of the major contributors to population dose from a geologic repository and that technologies for partitioning and transmutation of ${ }^{129} \mathrm{I}$ may eventually be developed. Based on water transport meihanisms, ${ }^{99} \mathrm{Tc}$ and ${ }^{129} \mathrm{I}$ are estimated to account for more than $99.99 \%$ of the hypothetical population dose; ${ }^{129} \mathrm{I}$ would account for $43 \% .^{4-4}$

b. J. D. Christian, WINCO, private communication, November 1992. 
An additional advantage of AIROX recycle, which in effect provides extended burnup, is the burning of ${ }^{99} \mathrm{TC}$. Based on information in the 1988 ORNL database ${ }^{c}$ and ORIGEN2 runs by EG\&G, ${ }^{d}$ about $14 \%$ less ${ }^{99}$ Tc would result at $99 \mathrm{MWd} / \mathrm{kg}$ burnup than that generated in three times the fuel inventory burned to $33 \mathrm{MWd} / \mathrm{kg}$. The smaller amount of ${ }^{99} \mathrm{Tc}$ produced, combined with the ${ }^{129} \mathrm{I}$ removed during AIROX processing, would account for about a $50 \%$ reduction in hypothetical population dose from a geologic repository if all spent fuels were recycled.

From a waste management perspective, the issues in this study that remain unresolved include the following:

- A determination whether spent fuel assembly hardware and cladding could be reused in any way in the nuclear industry and if it would be cost-effective.

- A determination of costs associated with repository disposal of GTCC wastes

- A determination of the ultimate disposition of ${ }^{85} \mathrm{Kr}$ (stored in pressurized cylinders) and ${ }^{129} \mathrm{I}$ (i.e., transmute, dispose of as GTCC waste, or dispose of as $L L W)$.

\subsection{AIroX-Reprocessed Spent fuel from a Repository Perspective}

ORIGEN2 calculations have been carried out for AIROX-recycled fuel, conventional oxide fuel, and a high-burnup oxide fuel. In the calculations for the AIROX fuel, it is assumed that iodine and the noble gases are completely removed from the fuel, $90 \%$ of the cesium and ruthenium are removed, and $75 \%$ of the tellurium and cadmium are removed during the AIROX process.

c. "Characteristics of Spent Fue1, High-Level Waste, and Other Radioactive Wastes which may Require Long-Term Isolation," Office of Civilian Radioactive Waste Management, DOE/RW/0184, June 1988.

d. Letter, P. Kuan, "Transmittal of ORIGEN2 Calculations for AIROX Fuel," PK23-92, August 17, 1992. 
The recycled fuel is spiked with enriched feed such that the total fissile content of the fuel is $3.5 \mathrm{wt} . \%$ versus $3.2 \mathrm{wt} . \%$ for conventional fresh fuel used in PWRs. The fresh fuel is irradiated to 33 GWd/MTU, with a typical PWR burn history. Following a 5-year cooling period, the fuel is AIROX-processed, refabricated, and burned again in the reactor with the same burn history as the fresh fuel.

Figure 4-1 shows a comparison of the decay heats of AIROX-recycled fuel, conventional fue1, and high-burnup PWR fuel with 4.2 wt.\% initial enrichment burned to $55 \mathrm{GWd} / \mathrm{MTU}$. The recycled fuel would have gone through two complete cycles in a reactor (six reload cycles) and thus would have attained 66 GWd/MTU.

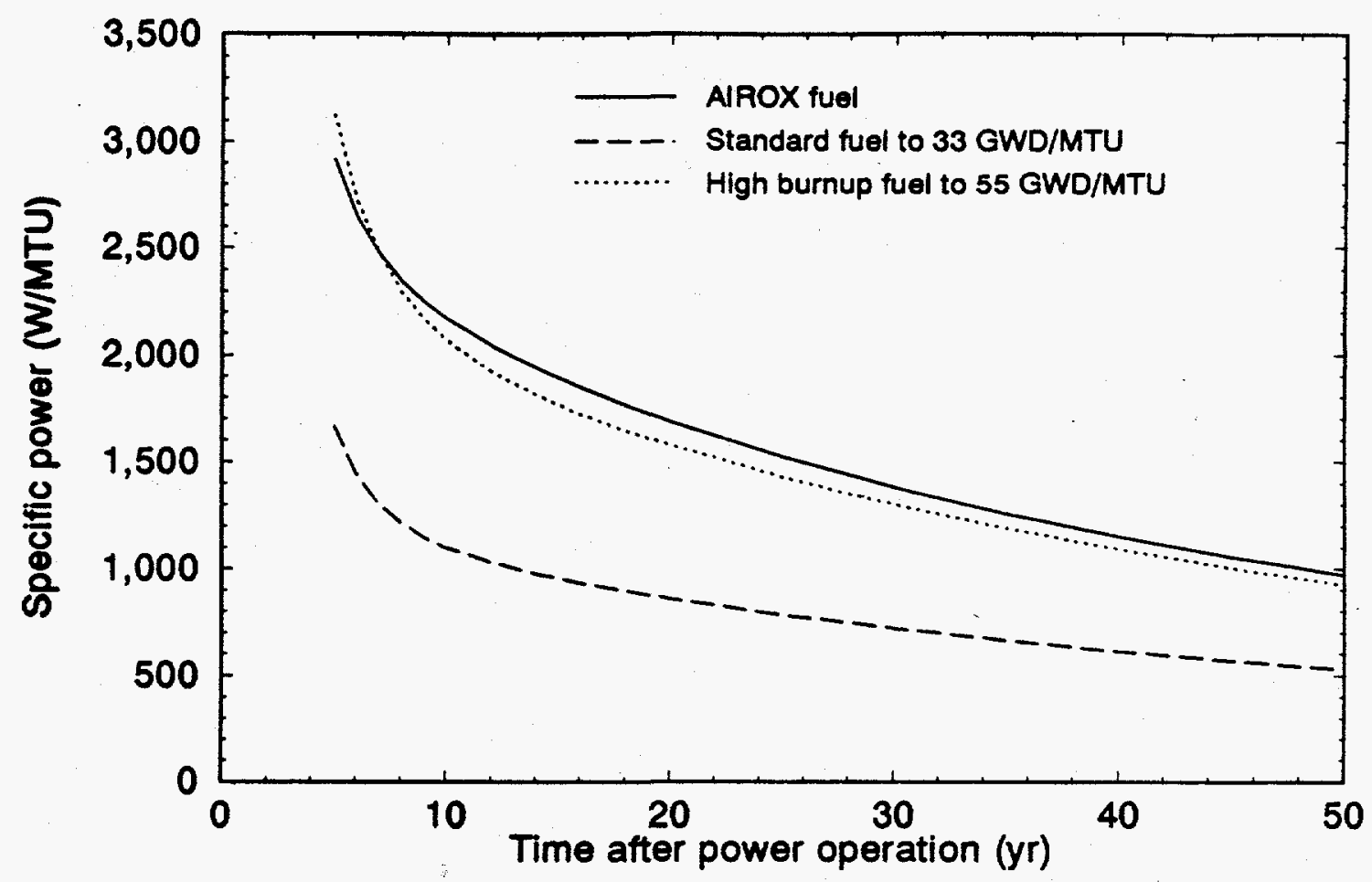

M773 pul-1292-03

Figure 4-1. Comparison of decay heat levels from AIROX fuel, standard 33 GWd/MTU burnup fuel, and 55 GWd/MTU fuel. 
During the initial 7-year period after reactor shutdown, the decay heat of the once-through, high-burnup fuel is approximately twice that of the lowburnup, conventional fuel. The decay heat from the AIROX-recycled fuel is slightly lower during this period than that of the high-burnup fuel, despite the AIROX-recycled fuel having a higher burnup. The relatively higher decay heat from the high-burnup fuel is mainly due to the accumulation of cesium, approximately half of which would have been removed if it were AIROX-processed during mid-cycle.

The above results show that, on a per-fuel-assembly basis, the AIROXrecycled spent fuel would have slightly less than twice the decay heat of conventional fuel. However, if the conventional fuel is recycled instead of replaced with fresh fuel, at the end of two cycles there would be one-half the number of AIROX-recycled spent fuel assemblies as compared to conventional spent fuel assemblies.

\subsection{IMPACT OF AIROX REPROCESSING ON U.S. Spent fuel Waste Reduction}

Part of this study involved a collaborative effort between Westinghouse Idaho Nuclear Co. (WINCO) and Westinghouse Hanford Co. (WHC) to build a systems analysis model to evaluate alternative technologies for processing and recycling spent LWR fuel. The model was intended to be a tool for making technological decisions if commercial incentives for recycling should become attractive due to rapidly changing world events, economics, and political policies. The model was built from the software ITHINK on a Macintosh workstation. As a base case, the impact of an AIROX recycle process on the generation rates of spent commercial nuclear fuel was modeled.

\subsubsection{AIROX Recycle Model and Assumptions}

Some of the attributes of the AIROX Recycle Model are shown in Figure 4-

2. The model was designed to maintain mass balance and track radionuclide content of all materials flowing into, recycled within, and flowing out of the for virgin feedstock to recycled fuel, and new fuel, as needed to maintain 


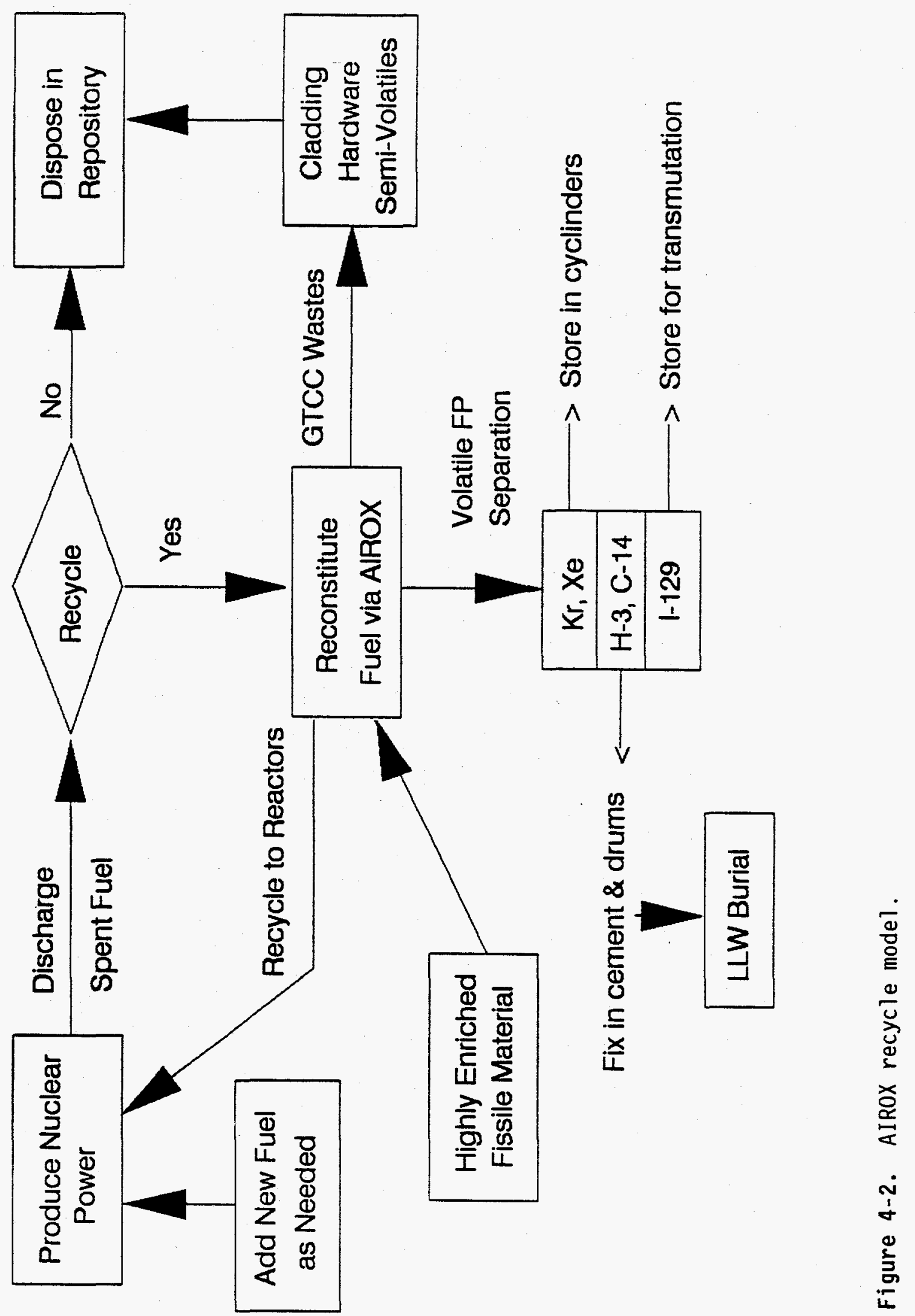


AIROX process. Up to four recycles of spent nuclear fuel can be modeled. Input material to the AIROX Recycle Model consisted of highly enriched $\mathrm{UO}_{2}$, sufficient fuel for nuclear power demands. The base case modeled used $1.4 \%$, $3.2 \%, 3.54 \%$, and $17 \%$ fissile content for the spent fuel, new fuel, reconstituted fuel, and virgin makeup $\mathrm{UO}_{2}$, respectively. Output material from the AIROX Recycle Model consisted of spent fuel (not reprocessed) being shipped to a Federal repository; cladding, hardware, and semi-volatile wastes going to a Federal repository; and volatile fission products going to LLW burial and on-site storage. Inventories were tracked as MT of GTCC wastes, volume of LLW, number of gas cylinders, and volume of iodine-loaded adsorbent generated per MTIHM of spent fuel processed. Radioactive content, decay, and heat loads in AIROX-generated wastes were tracked. Radioactive buildup, heat loads, and reactor burning of ${ }^{99} \mathrm{Tc}$ in reconstituted fuels versus number of recycles were also tracked. Assumptions used in the model are given in Table $2-1$, in Section 2.2.1, and in Section 4.1.

\subsubsection{AIROX Recycle Model Predictions}

To model potential impacts of AIROX recycling on the $U . S$. nuclear fue 1 cycle, forecasts by DOE's Energy Information Administration (EIA) on the generation of spent commercial fuel were used. "Figure 4-3 illustrates the EIA projections of accumulative spent fuel between the years 2000 and 2040 for the no-new reactor orders case $(84,100$ MT by 2040) and the upper-reference reactor case $(151,600$ MT by 2040). The no-new reactor case assumes the U.S. nuclear power capacity will peak at 104 gigawatts-electric $\left(G_{\mathrm{e}}\right)$ by 2000 , decrease to $54 \mathrm{GW}_{0}$ by 2020, and all reactors will be shut down by 2040 . The upper-reference reactor case assumes that the U.S. nuclear power capacity will increase to $146 \mathrm{GW}_{e}$ in the year 2020 and peak at about $200 \mathrm{GW}_{e}$ in the year 2030.

e. Draft Mission Plan Amendment, Appendix B, "Projection of Spent-Fue Discharges, Types of Waste to be Accepted, and Waste-Acceptance Schedule," U.S. Department of Energy, Office of Civilian Radioactive Waste Management, September 1991. 


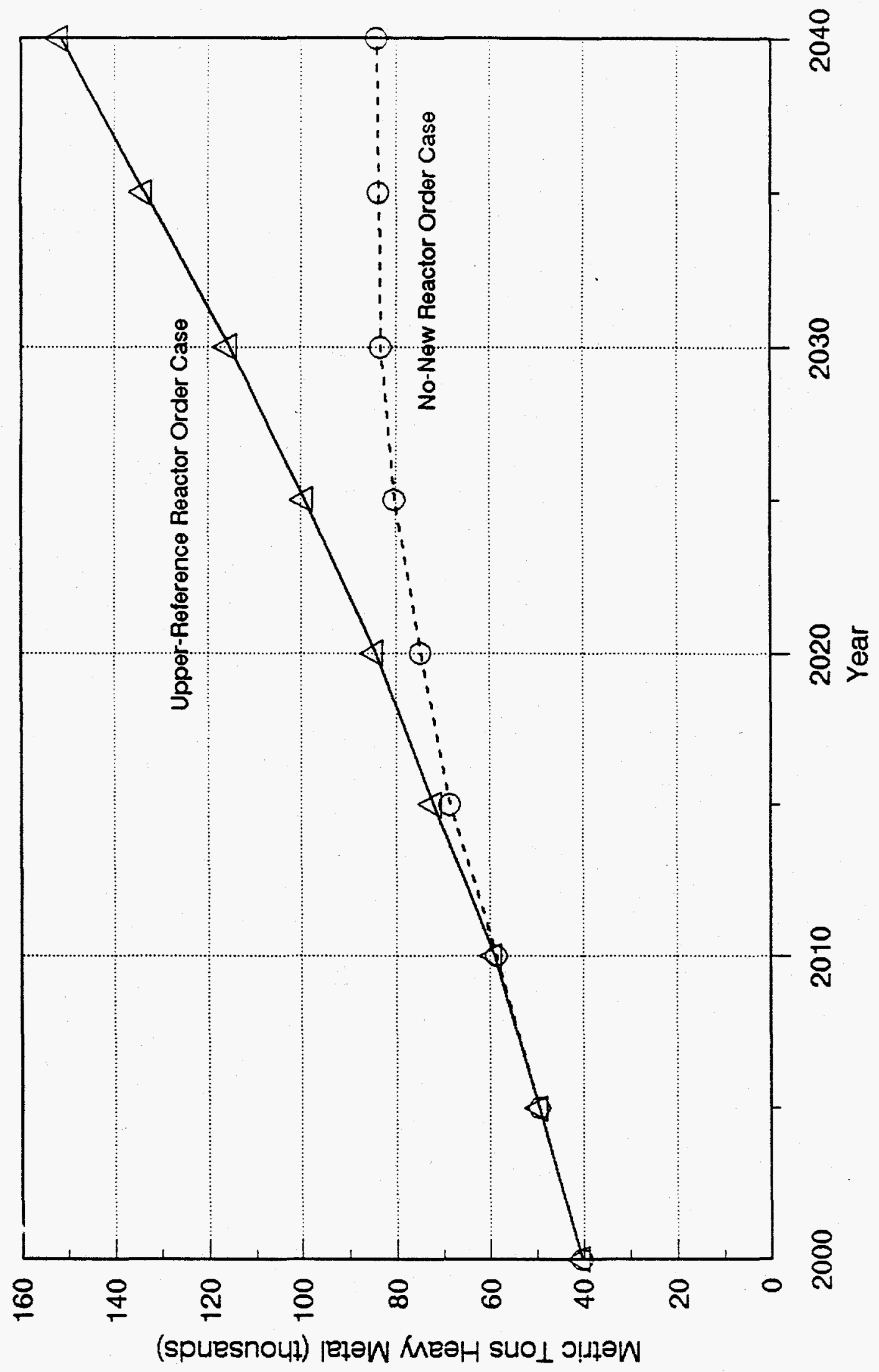

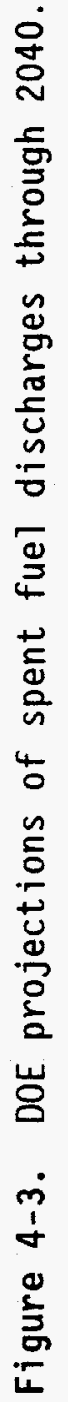


Figure 4-4 illustrates the comparative amounts of wastes generated without and with AIROX recycle for the no-new reactor case. The scenario assumes that no spent fuels are shipped to a Federal repository before 2040, spent fuel is recycled only once, and an AIROX recycle capacity of 1000 and $2000 \mathrm{MT} / \mathrm{y}$ of reconstituted fuels is achieved by the years 2005 and 2015, respectively. The upper solid line with circles represents the EIA projection for accumulative spent fuel versus time, as given in Figure 4-4. The lower solid line represents the amount of accumulative spent fuel and GTCC waste versus time with AIROX recycle. This curve is the sum of GTCC waste (dashdot-dash line), the recycled spent fuel inventory (dashed line), and the oncethrough spent fuel (dotted line). The accumulation of recycled spent fuel initially lags behind GTCC waste buildup because the model accrues GTCC waste the same year spent fuel is recycled, whereas recycled spent fuel is not accrued until about 4.5 years later when it is discharged from the reactor. As the upper two curves indicate, only a small reduction in wastes (about 11\%) would result from this scenario, because most of the once-through spent fuel would be generated before sufficient AIROX recycle capacity is implemented.

Figure 4-5 illustrates the comparative amounts of wastes generated without and with AIROX recycle for the upper-reference reactor case. The scenario assumes that no spent fuels are shipped to a Federal repository before 2040, spent fuel is recycled only once, and AIROX recycle capacities of 1000,2000 , and 4000 MT/y are achieved by the years 2005, 2015 and 2025, respectively. This scenario indicates that most of the once-through spent fuel (dotted line) would be recycled by 2040 (about 8 MT remains). The sum of the once-through spent fuel, the recycled spent fuel (dashed 1 ine), and the GTCC waste (dash-dot-dash 7 ine) at 2040 indicate a $31 \%$ reduction in generation of wastes.

The scenarios modeled in Figure 4-4 and 4-5 indicate that recycling spent fuel could have a large impact in reducing spent fuel inventories for an expanding or constant nuclear fuel economy. In the upper-reference case scenario, the once-through spent fuel inventory would be depleted by about 2042; and recycle of the once-recycled spent fuel would begin. In the idealized case (in which $95 \%$ enriched makeup or weapons material were 


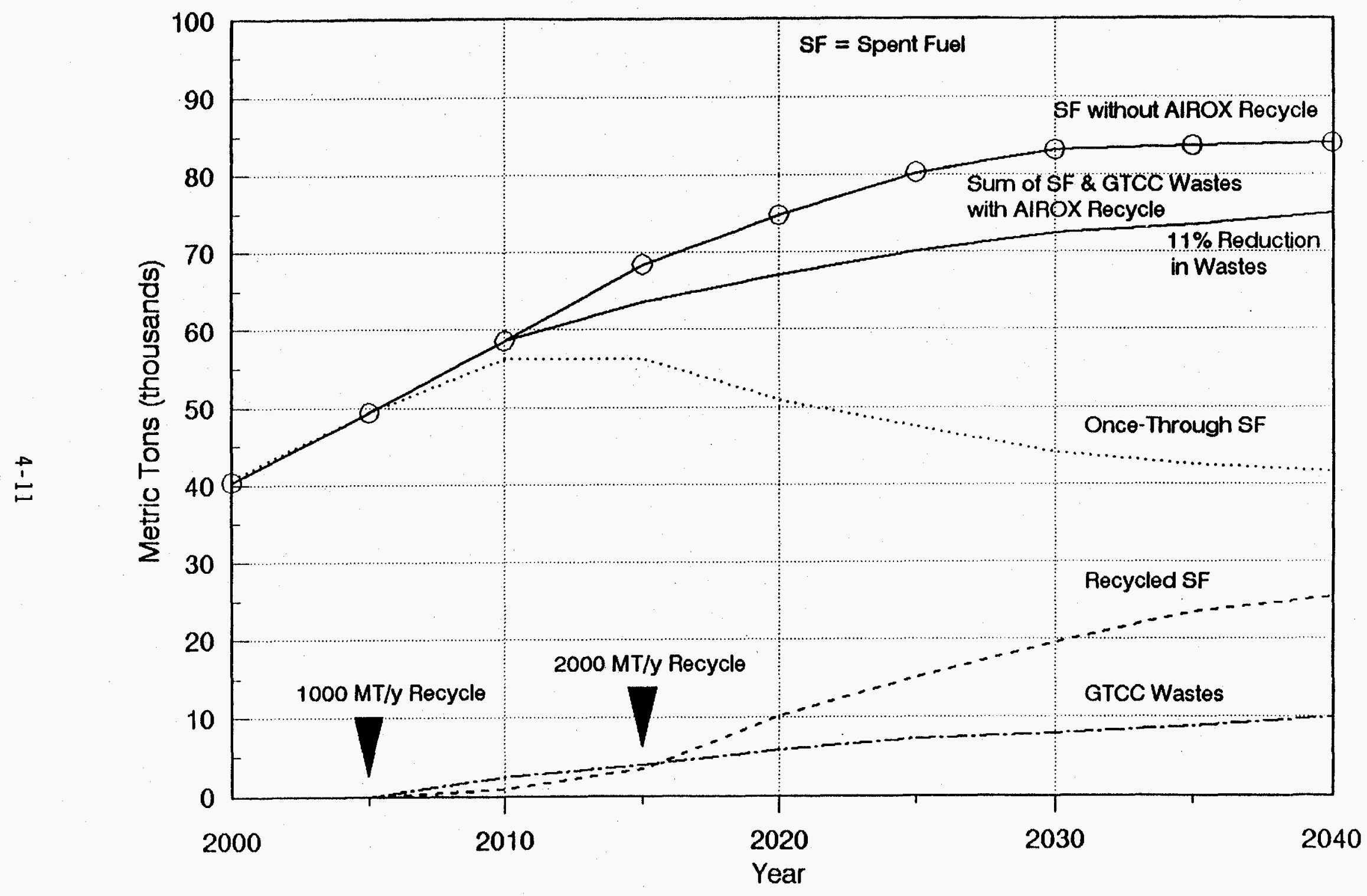

Figure 4-4. Wastes from once-through versus AIROX recycle scenarios for the no-new reactor case. 


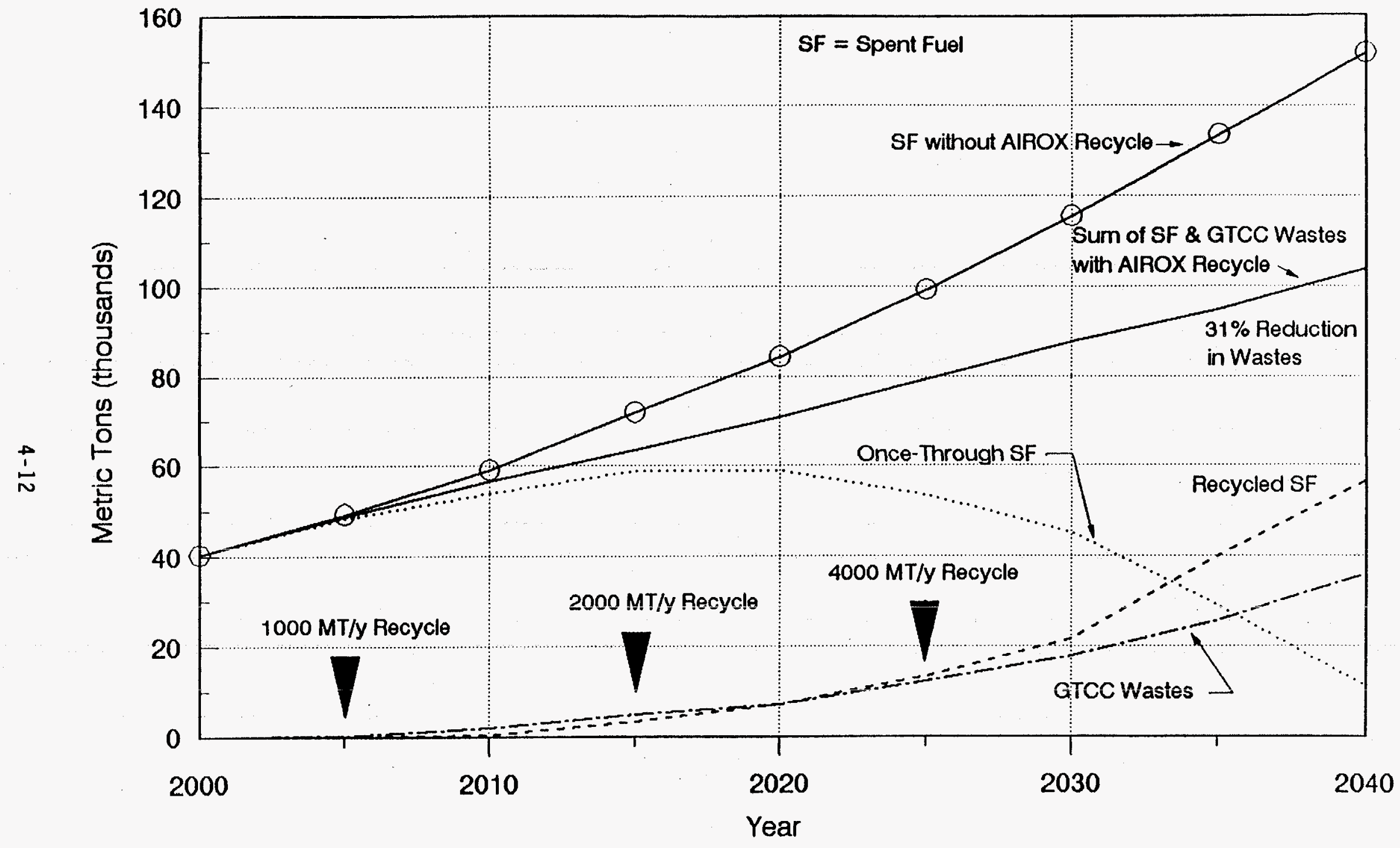

Figure 4-5. Wastes from once-through versus AIROX recycle scenarios for the upper-reference reactor case. 
available), recycled fuel burned to $120 \mathrm{MWd} / \mathrm{kg}$ would produce four times the electricity but about one fourth the spent fuel inventory that would result from burning once-through fuel to $33 \mathrm{MWd} / \mathrm{kg}$. AIROX recycling would be analogous to extended burnup of once-through spent fuel. The GTCC wastes would accumulate from each recycle; and, after four recycles, would contribute about 1.56 MT of wastes per MT of spent fuel passed through the AIROX process. However, the potential for GTCC waste reduction exists, particularly if methods for recycle of the cladding and hardware are developed and higher ${ }^{134} \mathrm{Cs} /{ }^{137} \mathrm{Cs}$ waste loadings in $\mathrm{glass}$ are achieved by allowing the ${ }^{134} \mathrm{Cs}$ to decay.

\subsection{References}

4.1 A. T. Luksic et al., Spent Fuel Disassembly Hardware and Other Non-Fuel Bearing Components: Characterization, Disposal Cost Estimates, and Proposed Repository Acceptance Requirements, PNL-6046, October 1986.

4-2. A. T. Luksic et a1., Spent Fuel Assembly Hardware: Characterization and 1OCFR61 Classification for Waste Disposa7, PNL-6903, June 1989.

4-3. R. D. Klett, Editor, Krypton-85 Disposal Program Conceptual Design Phase: Final Report, SAND-81-1957, November 1981.

4-4. T. H. Pigford, Actinide Burning and Waste Disposal, UCB-NE-4176, October 1990. 


\section{CONCLUSIONS AND RECOMMENDATIONS}

The revitalization of nuclear power in the U.S. depends, to a large extent, on implementing a method for disposing of high-level waste. In this context, the concept of recycling spent nuclear fuel, resulting in better resource utilization, has a very attractive ring, both from a technical and public perception perspective. This problem is not so severe in other countries because they have established a policy of reprocessing. This allows them to gainfully utilize the fissile material left in the spent fuel and pursue several avenues for disposal of the long-lived radioactive waste.

In this report, we have presented the results of an investigation of AIROX dry processing as an option for U.S. high-level waste management. Implementation of the AIROX process would not eliminate the need for a highlevel waste repository; however, it could provide flexibility in when or how big a repository would be necessary. As we have discussed, it has some advantages but it is not free from problems. The possible advantages to AIROX reprocessing are:

- Better utilization of our resources; AIROX recycling would mean more electricity generation per unit of spent nuclear fuel

- By recycling nuclear fuel instead of using direct disposal, AIROX reprocessing will result in less volume of total repository waste

- AIROX reprocessing would reduce the need by utilities for rapid expansion of on-site spent fuel storage

- AIROX reprocessing would provide more flexibility in the U.S. DOE's MRS and repository programs

- Weapons fissile material could be used in existing LWRs

- Economic benefit is achievable through large-scale implementation. 
AIROX reprocessing can also provide flexibility in high-level waste management by providing a front-end process for partitioning of radionuclides in the fuel material. By separating out the iodine and burning some of the technetium, the toxic source term for the repository would be reduced. Research and commercialization of spent fuel recycling and high-level waste partitioning technologies could minimize current barriers to public acceptance of a repository, encourage closure of the nuclear fuel cycle, and promote further development and use of nuclear power in the U.S.

INEL work over the last year has also revealed several areas where more knowledge is needed and/or improvements are required. First, the obvious disadvantage is that additional LLW will be generated at the AIROX processing facility, both during operation and upon decommissioning of the facility. Although LLW is a less serious problem, a cost-berefit analys is will have to be performed. Second, fabrication and inspection of new fuel from AIROX processing must be performed remotely, due to residual fission product activity. Current fuel fabrication and inspection are performed hands on. Effective technologies must be developed to assist utilities in applying AIROX-recycled fuel in their fuel management schemes. Third, the spent fuel elements from this recycling process will be hotter and will be similar to high-burnup fuel. This must be factored into the repository design. Finally, the AIROX process has not been tested beyond the laboratory scale. In addition to several development tasks identified in the text, a demonstration program, involving operation of recycled fuel assemblies in power reactors, is required before the technology can be used commercially.

In conclusion, our investigation shows that there is no noteworthy significant issue that eliminates AIROX from further development and demonstration of the technology; at the same time, there is no urgency or clamoring for the development of the AIROX recycling concept. Uncertainties with the once-through fuel cycle in the U.S., and safeguarding concerns with other reprocessing cycles, may encourage the AIROX recycling concept. It has the additional potential for relieving the urgency of repository development. We recommend the following three tasks for this program:

1. Perform an economic analysis to determine if an initial investment 
in a demonstration program has the required payoff.

2. Develop a program plan (with budget and schedule) enumerating how much it will cost the Government and industry to demonstrate this technology to the point where it can be commercialized.

3. Work with the utility and nuclear industry to determine if a consensus can be developed for the AIROX recycling concept. 